\title{
Rosmarinic Acid and Sodium Citrate Have a Synergistic Bacteriostatic Effect against Vibrio Species by Inhibiting Iron Uptake
}

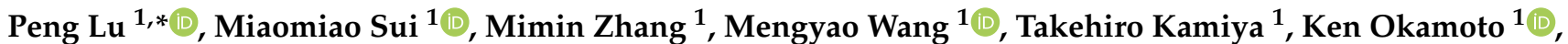 \\ Hideaki Itoh ${ }^{1}$, Suguru Okuda ${ }^{1}$, Michio Suzuki ${ }^{1}$, Tomiko Asakura ${ }^{1}$, Toru Fujiwara ${ }^{1}$ and Koji Nagata ${ }^{1,2, *(\mathbb{D})}$ \\ 1 Department of Applied Biological Chemistry, Graduate School of Agricultural and Life Sciences, \\ The University of Tokyo, 1-1-1 Yayoi, Bunkyo-ku, Tokyo 113-8657, Japan; \\ suimiaomiao1989@outlook.com (M.S.); zhangmimin001@hotmail.com (M.Z.); \\ wmy-puppet@outlook.com (M.W.); akamiyat@g.ecc.u-tokyo.ac.jp (T.K.); \\ akenokamoto@g.ecc.u-tokyo.ac.jp (K.O.); itohh@g.ecc.u-tokyo.ac.jp (H.I.); okuda@g.ecc.u-tokyo.ac.jp (S.O.); \\ amichio@g.ecc.u-tokyo.ac.jp (M.S.); asakura@g.ecc.u-tokyo.ac.jp (T.A.); atorufu@g.ecc.u-tokyo.ac.jp (T.F.) \\ 2 Agricultural Bioinformatics Research Unit, Graduate School of Agricultural and Life Sciences, \\ The University of Tokyo, 1-1-1 Yayoi, Bunkyo-ku, Tokyo 113-8657, Japan \\ * Correspondence: porterlu@g.ecc.u-tokyo.ac.jp (P.L.); aknagata@mail.ecc.u-tokyo.ac.jp (K.N.); \\ Tel.: +81-5841-5166 (P.L.); +81-5841-1117 (K.N.); Fax: +81-5841-5168 (P.L. \& K.N.)
}

Citation: Lu, P.; Sui, M.; Zhang, M.; Wang, M.; Kamiya, T.; Okamoto, K.; Itoh, H.; Okuda, S.; Suzuki, M.; Asakura, T.; et al. Rosmarinic Acid and Sodium Citrate Have a Synergistic Bacteriostatic Effect against Vibrio Species by Inhibiting Iron Uptake. Int. J. Mol. Sci. 2021, 22, 13010. https://doi.org/10.3390/ ijms222313010

Academic Editors: Yoshikazu Higami, Masaki Kobayashi and Akira Sato

Received: 5 November 2021

Accepted: 29 November 2021

Published: 1 December 2021

Publisher's Note: MDPI stays neutral with regard to jurisdictional claims in published maps and institutional affiliations.

Copyright: (c) 2021 by the authors. Licensee MDPI, Basel, Switzerland. This article is an open access article distributed under the terms and conditions of the Creative Commons Attribution (CC BY) license (https:/ / creativecommons.org/licenses/by/ $4.0 /$ )
Abstract: Background: New strategies are needed to combat multidrug-resistant bacteria. The restriction of iron uptake by bacteria is a promising way to inhibit their growth. We aimed to suppress the growth of Vibrio bacterial species by inhibiting their ferric ion-binding protein (FbpA) using food components. Methods: Twenty spices were selected for the screening of FbpA inhibitors. The candidate was applied to antibacterial tests, and the mechanism was further studied. Results: An active compound, rosmarinic acid (RA), was screened out. RA binds competitively and more tightly than $\mathrm{Fe}^{3+}$ to $\mathrm{VmFbpA}$, the FbpA from $V$. metschnikovii, with apparent $K_{\mathrm{D}}$ values of $8 \mu \mathrm{M}$ vs. $17 \mu \mathrm{M}$. Moreover, RA can inhibit the growth of $V$. metschnikovii to one-third of the control at $1000 \mu \mathrm{M}$. Interestingly, sodium citrate (SC) enhances the growth inhibition effect of RA, although SC only does not inhibit the growth. The combination of RA/SC completely inhibits the growth of not only $V$. metschnikovii at $100 / 100 \mu \mathrm{M}$ but also the vibriosis-causative pathogens $V$. vulnificus and $V$. parahaemolyticus, at 100/100 and 1000/100 $\mu \mathrm{M}$, respectively. However, RA/SC does not affect the growth of Escherichia coli. Conclusions: RA/SC is a potential bacteriostatic agent against Vibrio species while causing little damage to indigenous gastrointestinal bacteria.

Keywords: ferric ion-binding protein; vibriosis; Vibrio species; spice extracts; rosmarinic acid; bacteriostatic agent

\section{Introduction}

Vibrio is a genus of ubiquitous bacteria that inhabit a wide range of aquatic and marine environments and cause seafood contamination and infectious diseases in humans. More than 30 species of Vibrio have been discovered to date and $V$. cholerae, $V$. parahaemolyticus, $V$. alginolyticus, $V$. vulnificus, $V$. fluvialis, $V$. hollisaea, $V$. mimicus, and $V$. metschnikovii are among the most frequently isolated human pathogens. These bacteria are found in environments of moderate or high salinity, including in seawater and seafood, and they are agents of human vibriosis [1].

Sushi is a Japanese cuisine that is popular worldwide. People consume a large number of raw marine fishes, crustaceans, and shellfishes as sushi with soy sauce. However, eating raw seafood contaminated by microorganisms may cause disease; indeed, Vibrio-related seafood-borne diseases are rapidly increasing [2]. According to the Intergovernmental Panel on Climate Change (IPCC), on a global scale, the ocean surface is warming due to 
climate change. The upper $75 \mathrm{~m}$ near the ocean surface warmed by $0.11^{\circ} \mathrm{C}\left(0.09{ }^{\circ} \mathrm{C}\right.$ to $0.13^{\circ} \mathrm{C}$ ) per decade from 1971 to 2010 [3]. Since 2012, The European Food Safety Authority (EFSA) has been highlighting the emerging threat of Vibrio resulting from climate change. The increased surface seawater temperature and increased nutrient input in the ocean have spread Vibrio, causing outbreaks of seafood contamination [4].

According to the U.S. Centers for Disease Control and Prevention (CDC), the peak of Vibrio infection occurs from May to October, during which the climate is warmer than the rest of the year [5]. Such a warm season is generally recognized as the "Vibrio season" because it is suitable for Vibrio growth. Furthermore, this season is expanding into the all months, and the risk of infection is increasing [5]. From 1996 to 2010, a total of more than 7000 cases of Vibrio infection were reported in the United States [6]. However, because Vibrio bacteria are not easily identified with routine testing, there are even more cases not reported.

At present, CDC estimates that approximately 80,000 people per year are infected with Vibrio in the United States, of which about 52,000 of the infections are estimated to be the result of eating contaminated seafood. Every year, about 100 people die from the infection [7]. Therefore, it is urgent to take effective actions to decrease the risk of infection by Vibrio globally.

At the initial stage of this study, we targeted an infectious Gram-negative bacterium: $V$. metschnikovii. Although $V$. metschnikovii is less frequently reported than $V$. cholera, $V$. parahaemolyticus, and $V$. vulnificus, it will also be a potential emerging issue [8].

The abuse of non-biodegradable antibiotics in the food industry has promoted their persistence in aquatic environments for years. The direct cause for this is the development of antibiotic-resistance bacteria pathogenic to humans, fish, and other aquatic animals [9]. The emergence of antibiotic-resistance is threatening the usefulness of new bactericidal agents and suppressing drug development [10]. Therefore, there is a need to develop a new antimicrobial agent beyond antibiotics for the inhibition of $V$. metschnikovii growth.

Iron is a vital element in almost all living organisms. In the case of Vibrio, iron is the growth-limiting factor in nutrient-rich ocean environments. Low iron levels not only reduce the rate of growth of $V$. metschnikovii but also affect its survival and ability to persist [11]. As an alternative to antibiotics, the restriction of iron uptake is a potential antibacterial therapy [12]. To support general biological functions in bacteria, around $10^{-6}$ to $10^{-7}$ molar iron is required per cell [13]. Ferric ion-binding protein $(\mathrm{Fbp}) \mathrm{A}$ is a periplasmic-binding protein (PBP) from an ATP-binding cassette (ABC) transporter in Gram-negative bacteria, particularly for binding un-chelated or naked $\mathrm{Fe}^{3+}$ solubilized in the solution. This FbpA efficiently takes up iron together with the inner membrane transporter, FbpBC. Since FbpA is highly conserved among Gram-negative bacteria, $\mathrm{FbpAs}$ from various species are chosen as antibacterial targets and have been structurally or functionally studied [14]. Moreover, the antisense peptide nucleic acid of the FbpA gene has been reported to have bactericidal activity toward Neisseria meningitidis [15].

As a Gram-negative bacterium, V. metschnikovii has an FbpA termed VmFbpA. VmFbpA is responsible for $\mathrm{Fe}^{3+}$ binding in the periplasm and delivering $\mathrm{Fe}^{3+}$ into the cytoplasm by docking at the transmembrane domain and has a sequence similarity of $\approx 30 \%$ to the FbpAs of other pathogenic Vibrio species. Consequently, $\mathrm{VmFbpA}$ is a promising target protein for iron limitation.

As part of the Japanese culture of eating raw seafood, complementary ingredients are typically used to enhance the flavor. Spices are commonly introduced as flavor enhancers in the food industry, which is a practice that is widely accepted by the general population. This study was original because we inhibited bacterial growth by limiting iron uptake, rather than by using conventional antibiotics. Therefore, to lower the risk of oral infections by Vibrio species, specific spice extracts or chemicals that can both enhance the flavor of raw seafood and inhibit FbpA activity, to control the growth of Vibrio species, should be identified. 
Here, we report a natural inhibitor of $\mathrm{VmFbpA}$ from rosemary extract, rosmarinic acid (RA), which was screened out from 20 spices, and show that its antibacterial effect on several Vibrio species is enhanced in the presence of sodium citrate (SC).

\section{Results}

\subsection{Screening of VmFbpA Inhibitors from Aqueous Extracts of 20 Spices}

Assays for the inhibition of $\mathrm{Fe}^{3+}$ binding of $\mathrm{VmFbpA}$ were performed, and the remaining Fe concentrations were measured via ICP-MS using aqueous extracts of 20 spices at a final concentration of $2.5 \mathrm{mg} / \mathrm{mL}$ (Figure 1a). Only cinnamon and rosemary extracts decreased the remaining Fe concentration by more than $50 \%$ compared to the $\mathrm{Fe}^{3+}-\mathrm{VmFbpA}$ control group. Furthermore, no spice extracts increased the remaining Fe concentration higher than the $\mathrm{Fe}^{3+}-\mathrm{VmFbpA}$ control group. Therefore, cinnamon and rosemary extracts were considered candidate inhibitors of VmFbpA.

\subsection{Spectral Analysis of VmFbpA Interacting with $R A$}

To assess their dose-dependent effects on the inhibition of $\mathrm{Fe}^{3+}$ binding by VmFbpA, different concentrations $(0,0.9,1.9,3.8,7.5$, and $15 \mathrm{mg} / \mathrm{mL})$ of cinnamon and rosemary extracts were subjected to inhibition assays using UV-visible absorbance spectroscopy (Figure $1 \mathrm{~b}-\mathrm{e}$ ). In the case of cinnamon extracts, the color of the eluents changed from yellow to colorless and finally became dark red as the applied concentration increased (Figure 1b). In the case of rosemary extracts, the color of the eluents changed from yellow to colorless and finally became yellow again (this yellow color is the color from rosemary extracts but not $\mathrm{Fe}^{3+}$ ) as the applied concentration increased (Figure 1d). A significant peak shift (from $\approx 412 \mathrm{~nm}$ to $\approx 380 \mathrm{~nm}$ ) was observed in the spectra of the samples treated with rosemary extracts (Figure 1e). However, no such peak shift was observed in the samples treated with cinnamon extracts (Figure 1c). Consequently, rosemary extracts were selected for further analysis.

Second, a major component of rosemary extract, RA $(0,0.15,0.30,0.60,1.2$, and $2.4 \mathrm{mg} / \mathrm{mL}$ ), was subjected to an inhibition assay. Compared to the spectrum of $\mathrm{VmFbpA}$ or RA only, that of VmFbpA mixed with RA showed a specific peak (Figure 1f,g). In addition, a similar peak shift (from $\approx 412 \mathrm{~nm}$ to $380 \mathrm{~nm}$ ) to that caused by the rosemary extract was observed (Figure 1e).

\subsection{Quantitative Analysis of the Inhibition of $\mathrm{Fe}^{3+}$ Binding to VmFbpA by Rosemary Extracts and $R A$}

Rosemary extracts at $0,0.9,1.9,3.8,7.5$, and $15 \mathrm{mg} / \mathrm{mL}$, and $\mathrm{RA}$ at $0,6.5,13.0,26.0$, $52.0,104.0,208.0,416.3,832.6,1665.2,3330.5$, and $6661.0 \mu \mathrm{M}$, were used to determine the $\mathrm{IC}_{50}$ value (Figure $2 \mathrm{a}-\mathrm{d}$ ). The $\mathrm{IC}_{50}$ of rosemary extracts was $2.4 \pm 0.3 \mathrm{mg} / \mathrm{mL}$ and the $\mathrm{IC}_{50}$ of RA was $800 \pm 100 \mu \mathrm{M}(0.29 \pm 0.04 \mathrm{mg} / \mathrm{mL})$. 
a

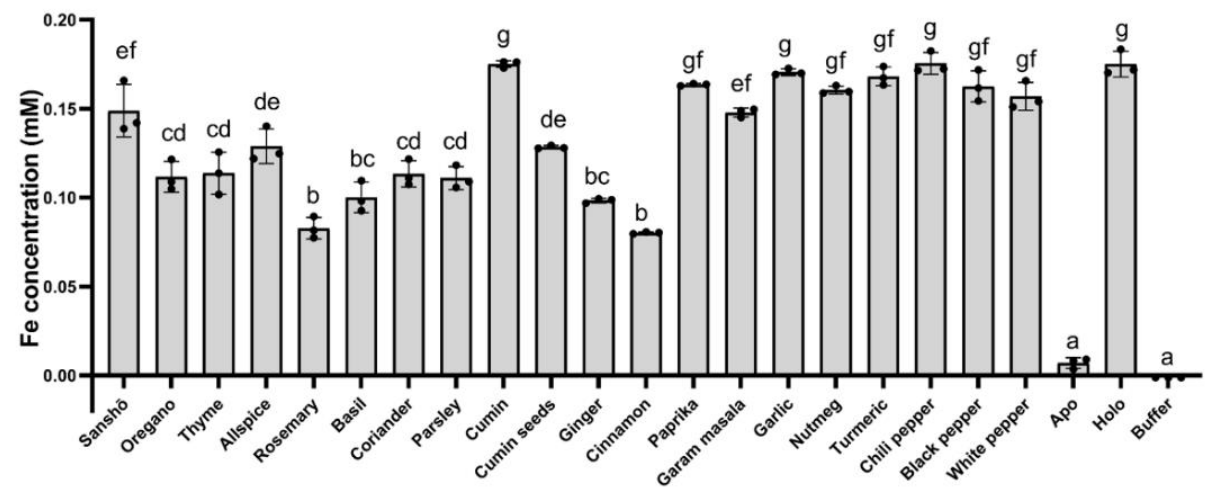

b

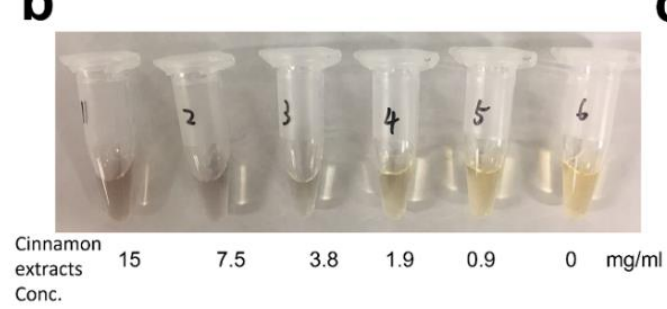

C
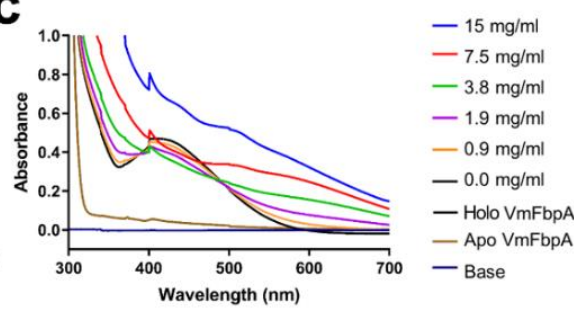

d

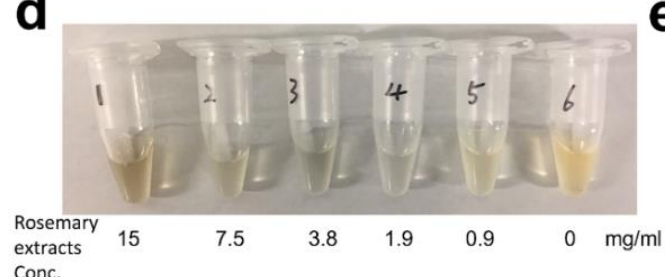

e

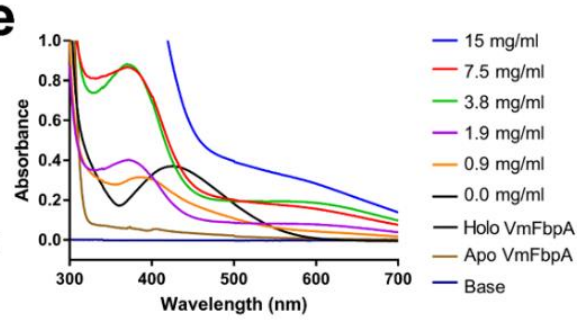

f

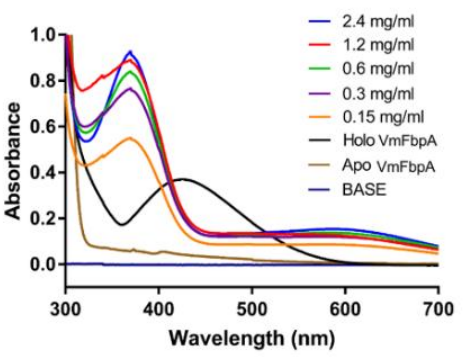

g

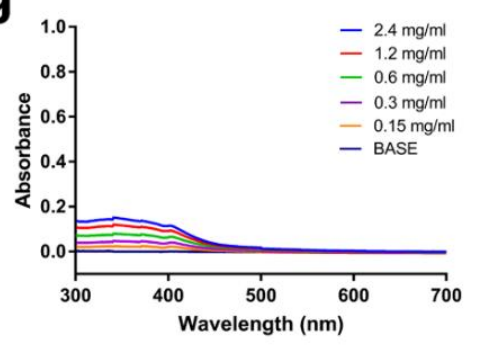

Figure 1. (a) Screening of $\mathrm{VmFbpA}$ inhibitors for $\mathrm{Fe}^{3+}$ binding. The gray bar represents the remaining Fe concentration after treatment with the extracts of 20 spices; $10 \mathrm{mM}$ EDTA was used as the negative control. In addition, apo $\mathrm{VmFbpA}$ (Apo) and $\mathrm{Fe}^{3+}-\mathrm{VmFbpA}$ (Holo) were also measured for comparison. Buffer represents the gel filtration buffer ( $50 \mathrm{mM}$ Tris- $\mathrm{HCl}$ (pH 8.0), $50 \mathrm{mM} \mathrm{NaHCO}$, and $150 \mathrm{mM} \mathrm{NaCl}$ ) used in $\mathrm{VmFbpA}$ purification. Data are means $\pm \mathrm{SD}$. Means with the same letter are not significantly different from each other $(p<0.05)(\mathbf{b})$ Eluents after inhibition assays using cinnamon extracts. (c) Absorbance spectra $(300-700 \mathrm{~nm}$ ) of the respective eluents shown in (b). (d) Eluents after inhibition assays using rosemary extracts. (e) Absorbance spectra (300-700 nm) of the respective eluents shown in (c). Spectra of apo and $\mathrm{Fe}^{3+}-\mathrm{VmFbpA}$ (controls). (f) Absorbance spectra (300-700 nm) of RA binding to apo VmFbpA. (g) Absorbance spectra (300-700 nm) of RA only. Base is elution buffer containing $50 \mathrm{mM}$ Tris- $\mathrm{HCl}(\mathrm{pH} 8.0), 50 \mathrm{mM} \mathrm{NaHCO}$, $150 \mathrm{mM} \mathrm{NaCl}$, and $250 \mathrm{mM}$ imidazole. 
a

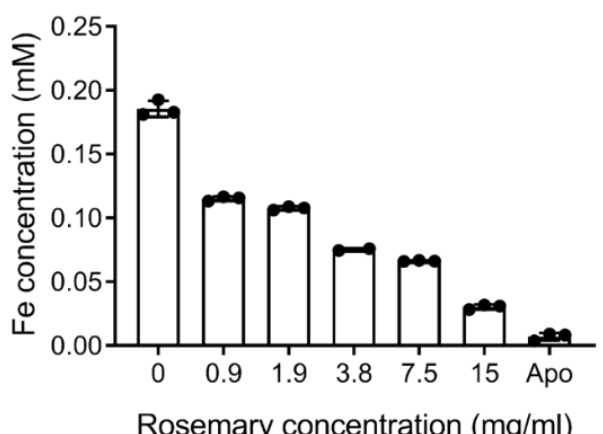

C

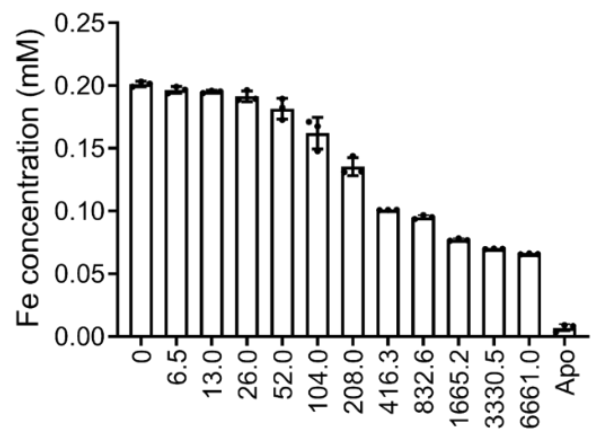

RA concentration $(\mu \mathrm{M})$

e

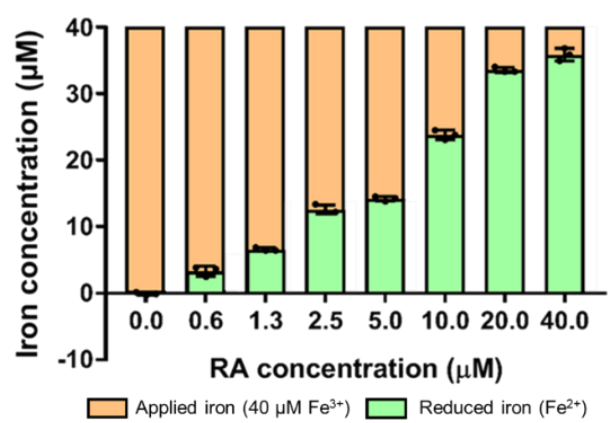

b

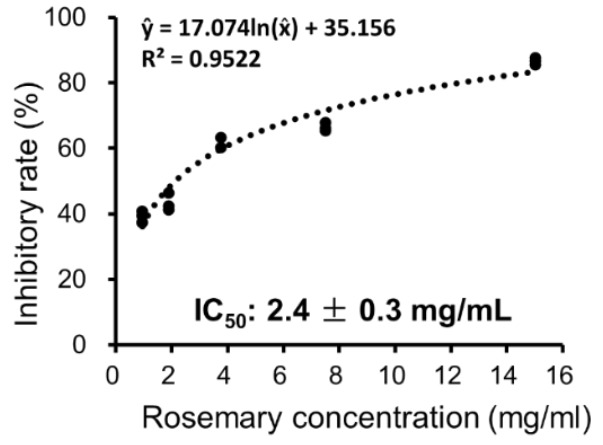

d

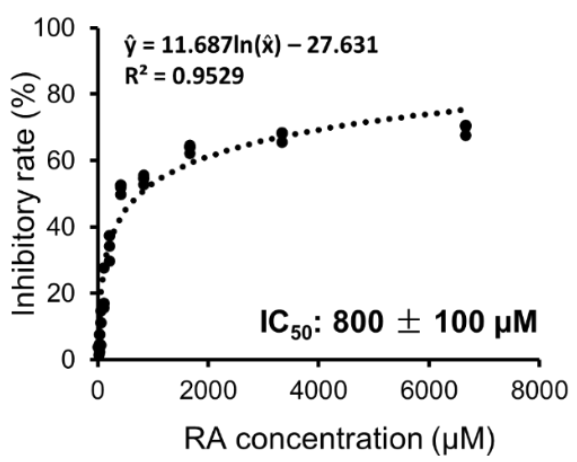

f

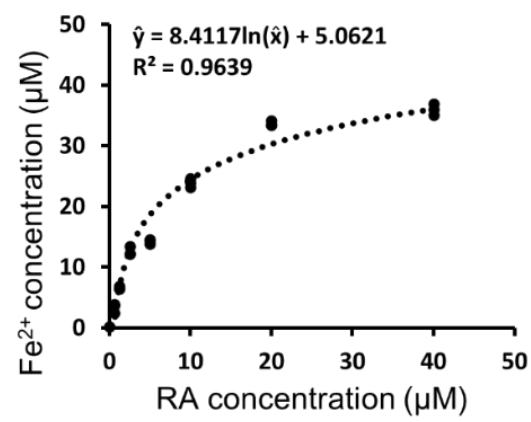

Figure 2. (a) The remaining Fe concentrations in the eluents after inhibition assays using rosemary extracts. (b) Inhibitory rates of rosemary extracts. A nonlinear regression model was performed to fit the concentration (rosemary)-response (inhibitory rate) data. (c) The remaining Fe concentrations in the eluents after inhibition assay using RA. (d) Inhibitory rates of RA. A nonlinear regression model was performed to fit the concentration (RA) - response (inhibitory rate) data. (e) The reduced $\mathrm{Fe}^{2+}$ concentration after adding RA $(0,0.6,1.3,2.5,5,10,20$, and $40 \mu \mathrm{M})$. Orange bar, applied $\mathrm{Fe}^{3+}(40 \mu \mathrm{M})$. Green bar, reduced $\mathrm{Fe}^{2+}$ from $\mathrm{Fe}^{3+}$ by RA. (f) A nonlinear regression curve fitting of the concentration (RA)—response $\left(\mathrm{Fe}^{2+}\right)$ data.

The reduction of $\mathrm{Fe}^{3+}$ to $\mathrm{Fe}^{2+}$ by $\mathrm{RA}$ was evaluated by mixing $40 \mu \mathrm{M} \mathrm{FeCl}_{3}$ with various concentrations of RA (Figure 2e,f). A dose-dependent effect of RA in reducing $\mathrm{Fe}^{3+}$ to $\mathrm{Fe}^{2+}$ was observed. According to the regression curve, $1 \mu \mathrm{M}$ RA can reduce $\approx 2.44 \mu \mathrm{M}$ $\mathrm{Fe}^{3+}$ to $\mathrm{Fe}^{2+}$.

The affinity between $\mathrm{RA} / \mathrm{Fe}^{3+}$ and $\mathrm{VmFbpA}$ was measured via ITC (Figure 3a-c). The best fit of the ITC data in Figure 3a was attained with a single-site model; the apparent association constant $\left(K_{\mathrm{A} \text {, app }}\right)$ was $1.3 \times 10^{5} \pm 0.2 \times 10^{4} \mathrm{M}^{-1}$. The apparent $K_{\mathrm{D}}$ of RA binding to $\mathrm{VmFbpA}$ was $\approx 8 \mu \mathrm{M}$ (Figure 3a), which is two-fold stronger than $\mathrm{Fe}^{3+}$ binding to $\mathrm{VmFbpA}$ (apparent $K_{\mathrm{D}} \approx 17 \mu \mathrm{M}$ ) (Figure 3c). However, a more complicated curve was obtained for ITC experiments using $\mathrm{Fe}^{3+}-\mathrm{VmFbpA}$, which could not be fit to any model (Figure $3 b$ ). The thermodynamic parameters for the reaction between RA and apo VmFbpA 
were $\Delta H=-15 \pm 9 \mathrm{kcal} / \mathrm{mol}$ and $\Delta S=-0.04 \pm 0.03 \mathrm{kcal} / \mathrm{mol} / \mathrm{deg}$, which are shown in Figure $3 \mathrm{~d}$.
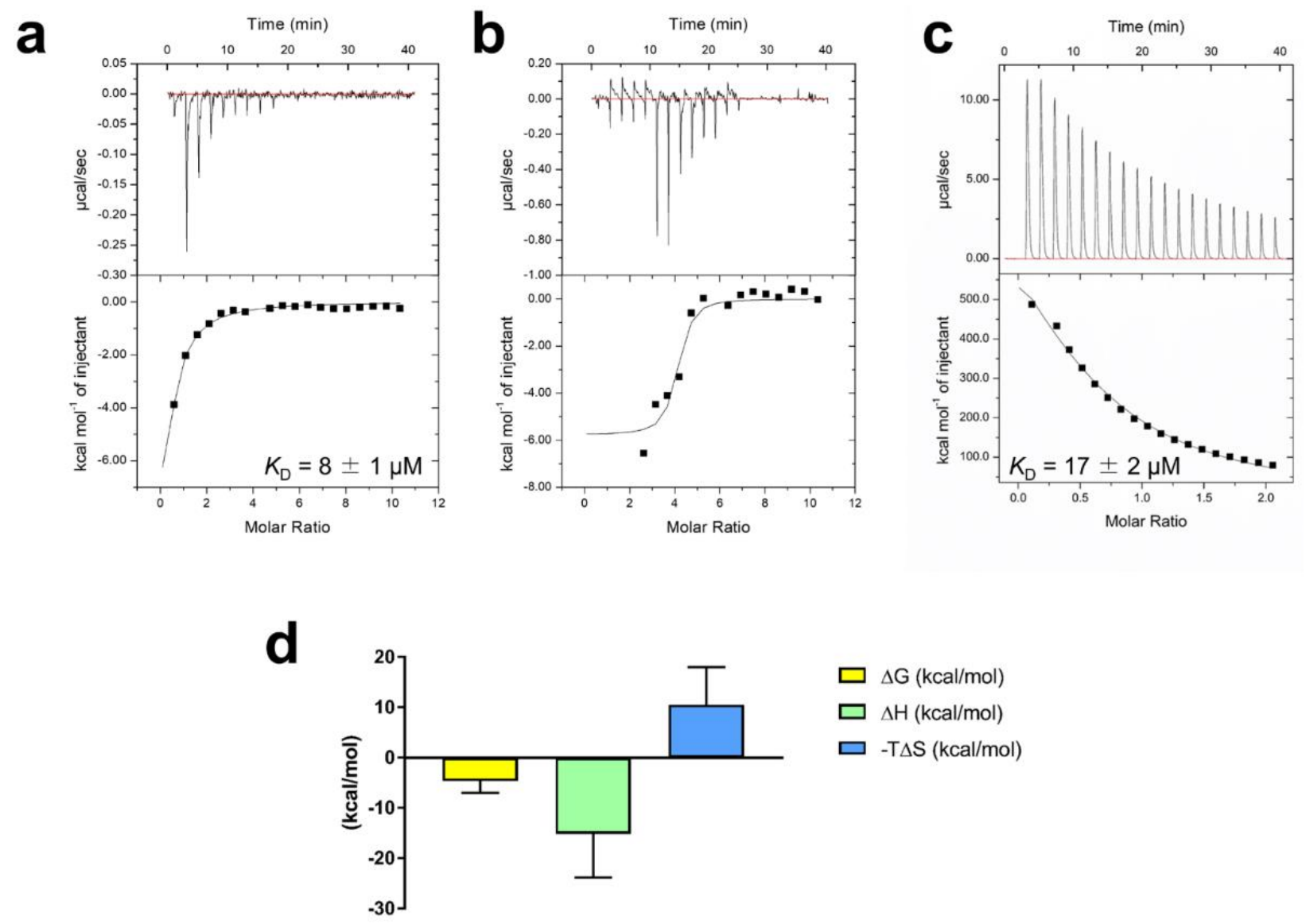

Figure 3. ITC analysis of RA binding to VmFbpA at $298 \mathrm{~K}$. (a) Binding between $10 \mu \mathrm{M}$ apo VmFbpA and $500 \mu \mathrm{M}$ RA. (b) Binding between $10 \mu \mathrm{M} \mathrm{Fe}{ }^{3+}-\mathrm{VmFbpA}$ and $500 \mu \mathrm{M}$ RA. (c) Binding between $10 \mu \mathrm{M}$ apo VmFbpA and $100 \mu \mathrm{M} F e^{3+}$. (d) Thermodynamic parameters for the binding of RA to apo VmFbpA calculated according to the data in (a). The free energy of binding $(\Delta G$, light yellow bar) is the sum of the enthalpic $(\Delta H$, light green bar) and entropic (-T $\Delta S$, light blue bar) terms.

\subsection{Spectra Analysis of $\mathrm{Fe}^{3+}$ Interacting with $\mathrm{RA}$}

The interactions between $\mathrm{RA}$ and $\mathrm{Fe}^{3+}$ were also investigated (Figure S3), including the UV-visible absorbance spectra of RA supplemented with different concentrations of $\mathrm{FeCl}_{3}$ (Figure S3a). After subtraction of the respective $\mathrm{FeCl}_{3}$ spectra (Figure $\mathrm{S} 3 \mathrm{~b}$ ), the net spectra were obtained (Figure S3c). The net spectra showed two peaks $(\approx 290 \mathrm{~nm}$ and $\approx 320 \mathrm{~nm}$ ) in the spectrum of $20 \mu \mathrm{M}$ RA, whereas only one peak at $\approx 250 \mathrm{~nm}$ was observed with supplementation of 20,30, and $40 \mu \mathrm{M} \mathrm{FeCl}_{3}$. Moreover, the spectrum of $20 \mu \mathrm{M} \mathrm{RA}$ with supplementation of $10 \mu \mathrm{M} \mathrm{FeCl}_{3}$ showed an intermediate pattern during the peak shift from $\approx 290 \mathrm{~nm}$ and $\approx 320 \mathrm{~nm}$ to $\approx 250 \mathrm{~nm}$.

\subsection{Inhibition of Bacterial Growth by $R A$}

The bacteriostatic effect of RA on the growth of $V$. metschnikovii was assayed (Figure 4). The growth of $V$. metschnikovii in nutrient broth (NB) medium leads to a final $\mathrm{OD}_{600}$ value of $\approx 0.6$ after $5 \mathrm{~h}$ using a microplate spectrophotometer (Benchmark Plus, Bio-Rad). In the presence of $500 \mu \mathrm{M} R A$, the final $\mathrm{OD}_{600}$ value decreased to about one-half of the control group. In the presence of $1000 \mu \mathrm{M} R A$, the final $\mathrm{OD}_{600}$ value decreased to about one-quarter of the control group (Figure $4 \mathrm{a}$ ). The $\mathrm{OD}_{600}$ value at $7 \mathrm{~h}$ was used for statistical analysis. In the presence of $100 \mu \mathrm{M} R A$, the $\mathrm{OD}_{600}$ value at $7 \mathrm{~h}$ showed a statistically significant decrease 
$(p=0.026)$ compared to the control group. The $\mathrm{OD}_{600}$ value at $7 \mathrm{~h}$ further decreased as the RA concentration increased to $500 \mu \mathrm{M}$ and $1000 \mu \mathrm{M}$. In the presence of $500 \mu \mathrm{M} R A$, the $\mathrm{OD}_{600}$ value at $7 \mathrm{~h}$ decreased to $\approx 0.4(p<0.001)$ and in the presence of $1000 \mu \mathrm{M} R A$, the $\mathrm{OD}_{600}$ value at $7 \mathrm{~h}$ decreased to $\approx 0.18(p<0.001)$ (Figure $4 \mathrm{~b}$ ).

a

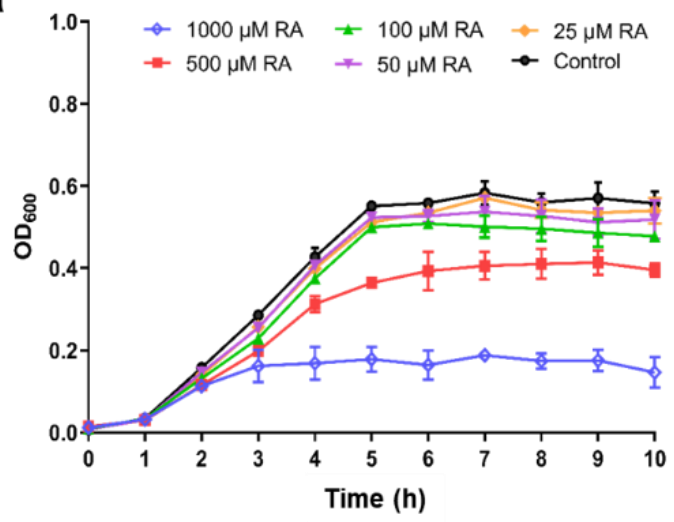

C

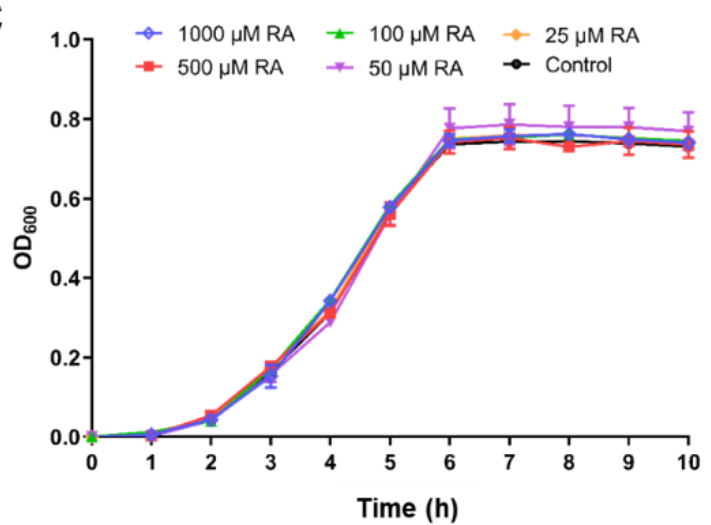

b

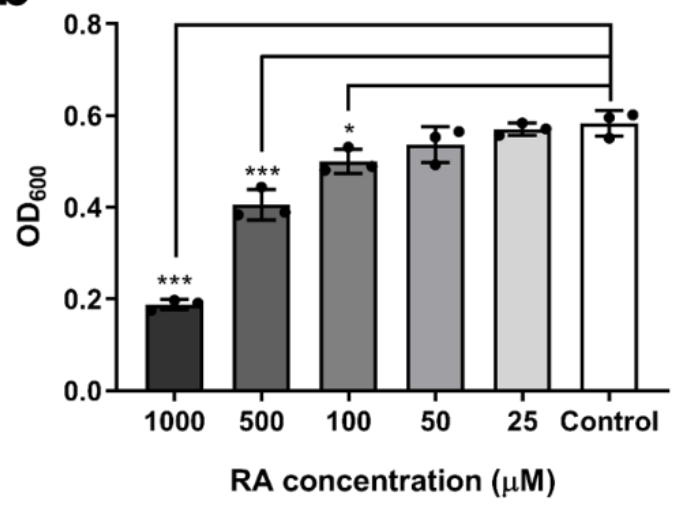

d

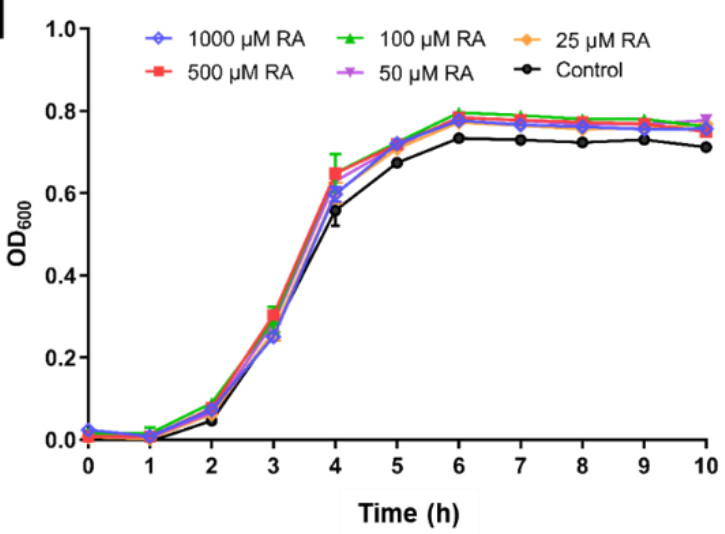

Figure 4. Antibacterial effect of RA. (a) Inhibitory effects of RA on V. metschnikovii growth from 0 to $10 \mathrm{~h}$. (b) Inhibitory effects of RA on $V$. metschnikovii growth at $7 \mathrm{~h}$. (c) Inhibitory effects of RA on E. coli (KRX) growth from 0 to $10 \mathrm{~h}$. (d) Inhibitory effects of RA on E. coli (BL21(DE3)) growth from 0 to $10 \mathrm{~h}$. RA was used at $0,25,50,100,500$, and $1000 \mu \mathrm{M}$. ${ }^{*} p<0.05$, $* * * p<0.001$.

The growth of E. coli BL21(DE3) and KRX in NB medium leads to a final $\mathrm{OD}_{600}$ value of $\approx 0.8$ after $5 \mathrm{~h}$ using a microplate spectrophotometer (Benchmark Plus, Bio-Rad, Hercules, $\mathrm{CA}, \mathrm{USA}$ ). However, the $\mathrm{OD}_{600}$ value and the bacterial growth curve were not affected by $\mathrm{RA}$ at $25 \mu \mathrm{M}$ to $1000 \mu \mathrm{M}$ (Figure $4 \mathrm{c}, \mathrm{d}$ ).

\subsection{Iron Utilization in V. metschnikovii}

The weight of $V$. metschnikovii after $7 \mathrm{~h}$ culture in NB medium decreased with increasing RA concentration (Figure 5a). The iron consumed by $V$. metschnikovii in all samples showed the same tendency, as measured using ICP-MS. The Fe utilization ratio decreased to half of the initial value after adding $100 \mu \mathrm{M} \mathrm{RA}(p=0.05)$ and further decreased to a quarter as the RA concentration increased to $1000 \mu \mathrm{M}(p<0.01)$ (Figure $5 b)$. The recovery of $V$. metschnikovii in the presence of $1000 \mu \mathrm{M}$ RA was investigated by supplementation of 10 and $50 \mu \mathrm{mol} \mathrm{FeCl}{ }_{3}$ to final concentrations of $1 \mu \mathrm{M}$ and $5 \mu \mathrm{M}$. When V. metschnikovii was supplemented with $1 \mu \mathrm{M} \mathrm{FeCl}_{3}$, slight recovery was observed, whereas after supplementation with $5 \mu \mathrm{M} \mathrm{FeCl}_{3}$, the recovery of $V$. metschnikovii was more obvious (Figure $5 \mathrm{c}$ ). Based on the $\mathrm{OD}_{600}$ value at $7 \mathrm{~h}$, the groups supplemented with $1 \mu \mathrm{M}(p<0.01)$ and $5 \mu \mathrm{M} \mathrm{FeCl}_{3}$ $(p<0.001)$ were significantly different from the negative control (Figure $5 \mathrm{~d}$ ). 


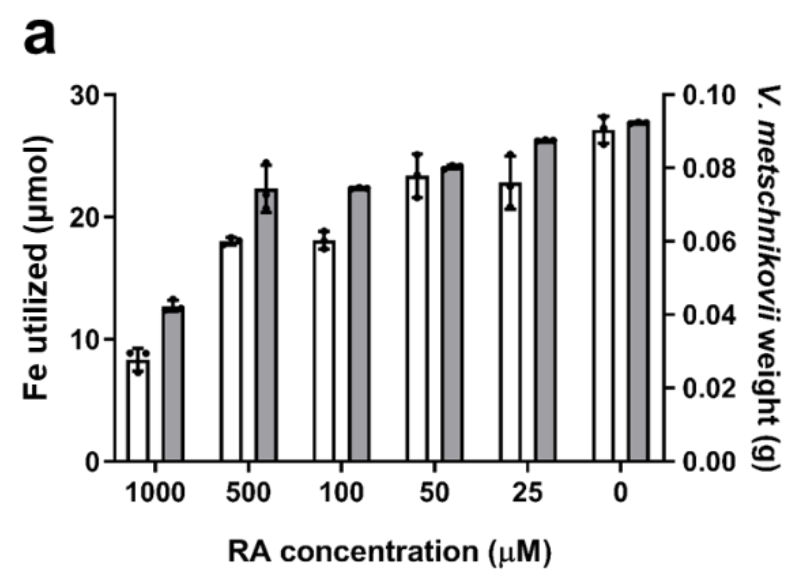

b

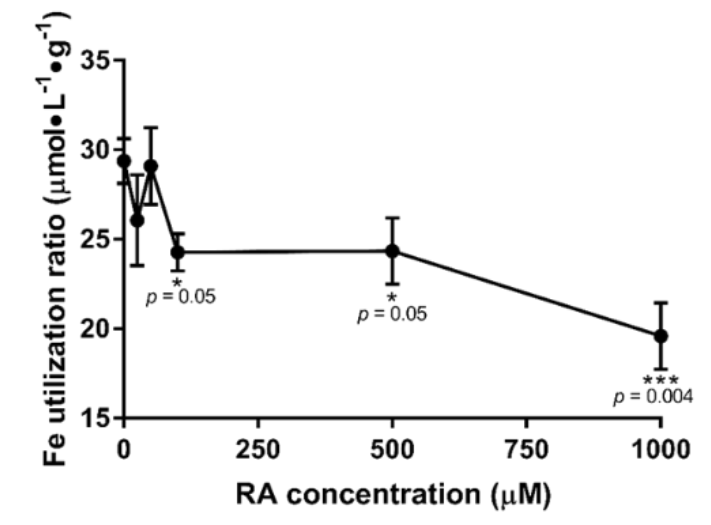

$\square$ Fe used $(\mu \mathrm{M}) \quad \square$ V. metschnikovii weight $(\mathrm{g})$
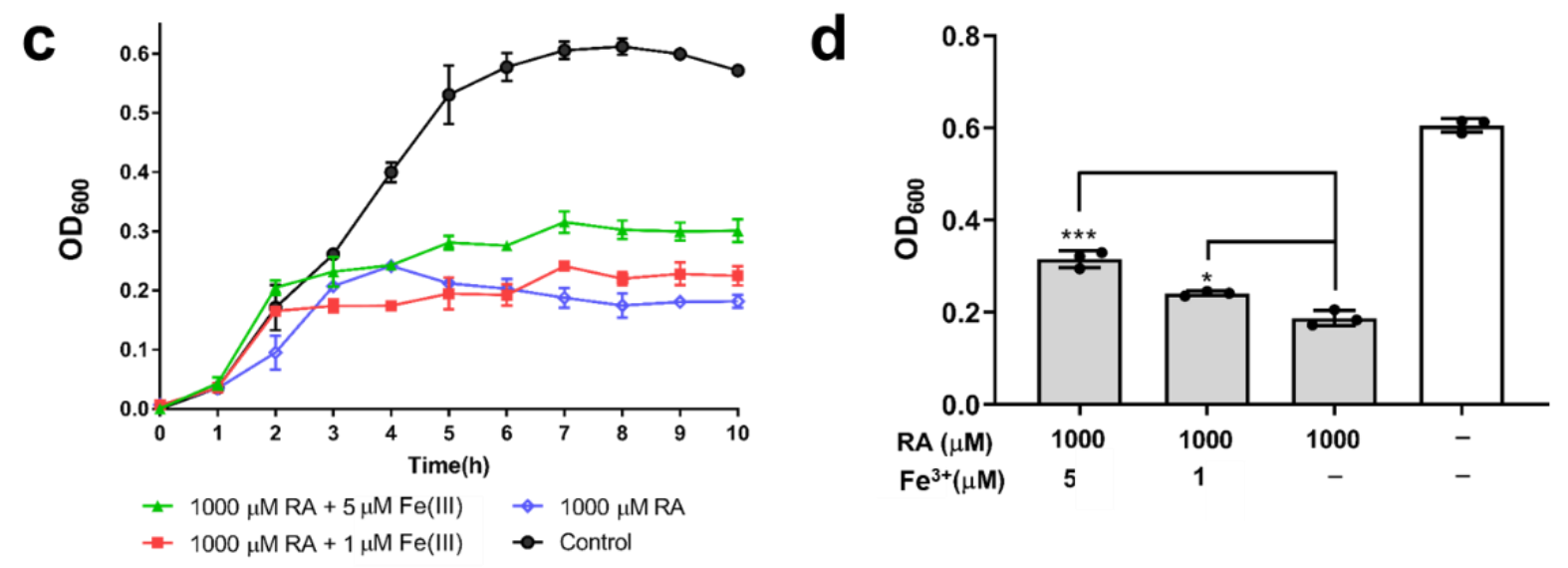

Figure 5. Iron utilization in V. metschnikovii and recovery of $V$. metschnikovii by adding $\mathrm{Fe}^{3+}$. (a) Weight and iron utilization of $V$. metschnikovii after $7 \mathrm{~h}$ of culture with RA $(0,25,50,100,500$, and $1000 \mu \mathrm{M})$. (b) Fe utilization ratio of V. metschnikovii after $7 \mathrm{~h}$ culture with RA $(0,25,50,100,500,1000 \mu \mathrm{M})$. (c) $V$. metschnikovii growth from 0 to $10 \mathrm{~h}$ in the presence of $1000 \mu \mathrm{M}$ RA with $\mathrm{FeCl}_{3}(10$ or $50 \mu \mathrm{M})$. (d) Growth recovery of $V$. metschnikovii at $7 \mathrm{~h}$ with $1000 \mu \mathrm{M}$ RA and supplementation of 1 or $5 \mu \mathrm{M} \mathrm{FeCl}_{3} \cdot{ }^{*} p<0.05,{ }^{* * *} p<0.001$.

\subsection{Inhibition by RA and Sodium Citrate (SC) of the Growth of V. metschnikovii}

The growth of $V$. metschnikovii was inhibited to $\approx 70 \%$ by $1000 \mu \mathrm{M} \mathrm{RA}$, and this inhibition was enhanced by 10,100, and $1000 \mu \mathrm{M} \mathrm{SC}$ (Figure 6a). Interestingly, the growth of $V$. metschnikovii was hardly inhibited by 10, 100, and $1000 \mu \mathrm{M}$ SC without adding $1000 \mu \mathrm{M}$ RA. The recovery of $V$. metschnikovii growth was observed as the RA concentration decreased from 1000 to $25 \mu \mathrm{M}$ RA in the presence of $100 \mu \mathrm{M}$ SC (Figure 6b).

The addition of RA or using the combination of RA and SC did not have a significant inhibitory effect on $E$. coli growth; all of the $E$. coli groups had an $\mathrm{OD}_{600}$ value of $\approx 0.8$ after incubation for $7 \mathrm{~h}$ in NB medium (Figure $6 \mathrm{c}, \mathrm{d}$ ). 
a

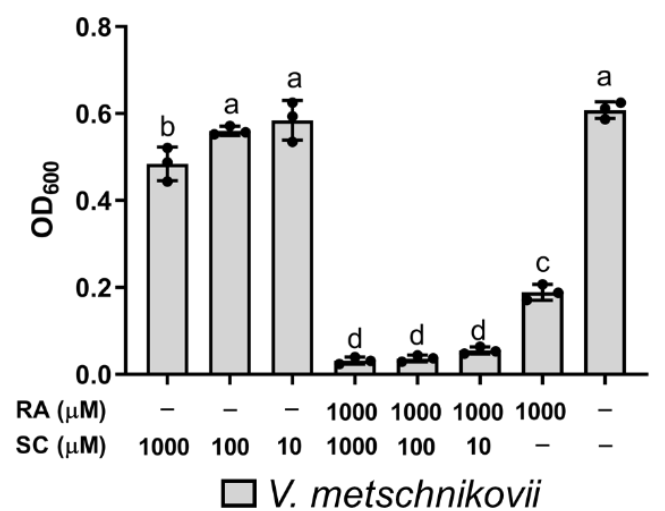

C

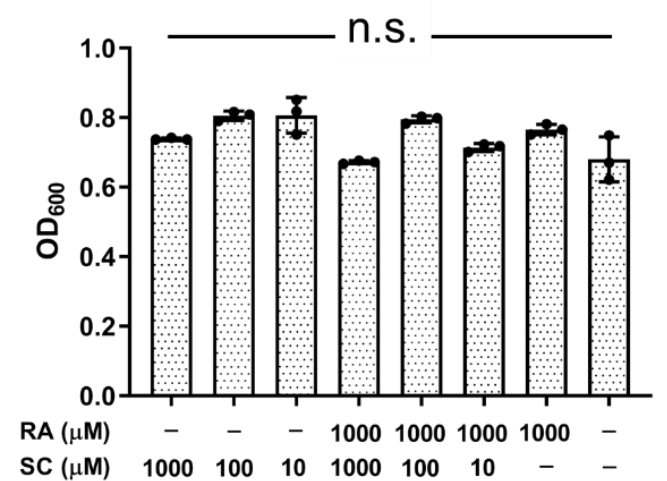

E. coli KRX b

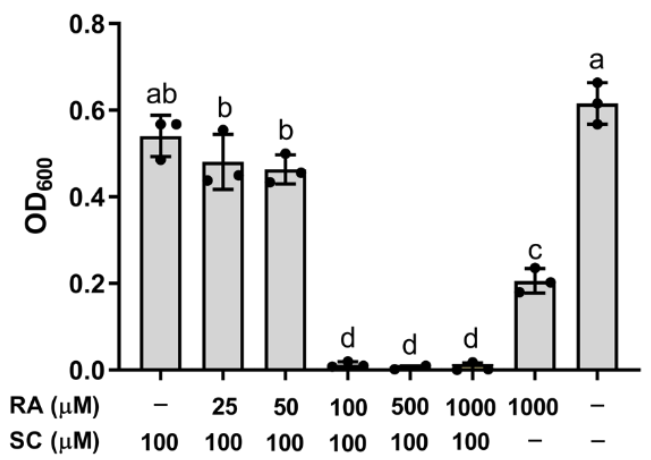

d

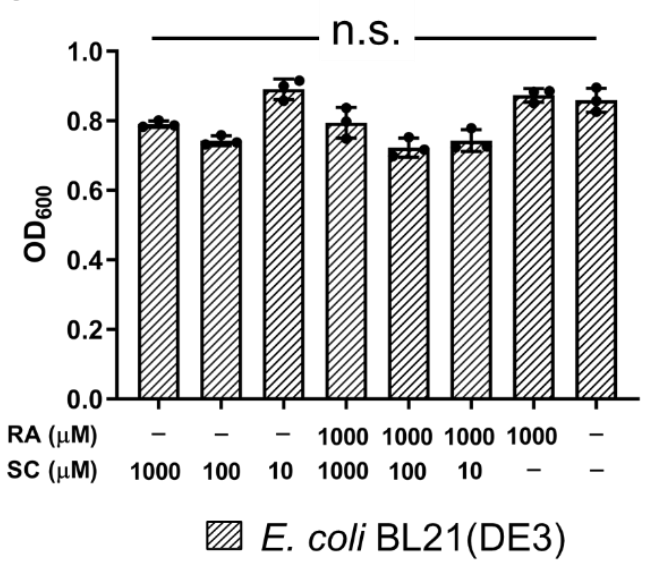

Figure 6. Antibacterial activity of the combination of RA and SC. (a) Dose-dependent effects of SC on V. metschnikovii inhibition with or without $1000 \mu \mathrm{M}$ RA. (b) Dose-dependent effects of RA with $100 \mu \mathrm{M}$ SC on V. metschnikovii inhibition. (c) Dose-dependent effects of SC on E. coli (KRX) inhibition with or without $1000 \mu \mathrm{M}$ RA. (d) Dose-dependent effects of SC with or without $1000 \mu \mathrm{M}$ RA on $E$ coli (BL21(DE3)) inhibition. Means with the same letter are not significantly different from each other $(p<0.05)$. n.s. represents no significant difference.

\subsection{Mechanism of RA Binding to VmFbpA}

The crystal structure of apo VmFbpA was determined by X-ray crystallography (Figure S4). Diffraction-quality crystals of apo VmFbpA were obtained with a reservoir composition of $0.25 \mathrm{M}$ ammonium tartrate dibasic, 25\% PEG3350, $100 \mathrm{mM}$ Tris- $\mathrm{HCl}$ ( $\mathrm{pH}$ 7.0). The apo VmFbpA crystal belonged to space group $P 6_{3} 22$, with unit-cell parameters $a=90.79$, $b=90.79$, and $c=149.68$ (Table S1). The crystal structure of apo VmFbpA was determined at $1.86 \AA$ resolution by molecular replacement using the structure of TtFbpA (PDB entry $3 \mathrm{WAE}$ ) as the search model. The final structure of apo $\mathrm{VmFbpA}$ contained one monomeric VmFbpA molecule (residues 1-309) and 238 water molecules in the asymmetric unit. Data collection and refinement statistics are summarized in Table S1. The Ramachandran plot of the apo VmFbpA structure shows that $99.35 \%$ and $0.65 \%$ of the residues are in the most favored and allowed regions, respectively. Second, the binding and inhibiting models were simulated in silico by docking analysis using Autodock vina. Three areas were selected as the potential docking regions for $\mathrm{VmFbpA}$ binding, namely C-Lobe, $\mathrm{N}$-Lobe, and $\mathrm{Fe}^{3+}$ binding site (Figure S5). The $\Delta G$ value for each model docking at the C-Lobe and N-Lobe was $0.0 \mathrm{kcal} / \mathrm{mol}$, whereas the $\Delta G$ value for the best model docking at the $\mathrm{Fe}^{3+}$ binding site was $\approx-7.0 \mathrm{kcal} / \mathrm{mol}$, indicating that $\mathrm{RA}$ binds $\mathrm{VmFbpA}$ at the $\mathrm{Fe}^{3+}$ binding site rather than C-Lobe and N-Lobe (Table S2). 
Inside the $\mathrm{Fe}^{3+}$ binding site, a total of nine models was presented by AutoDock (version Vina 1.1.2) (Figure 7, Table S3). In Model 1, six hydrogen bonds were formed between RA and VmFbpA. Amino acid residues R9, G140, N193, and V259 were involved in the interaction (Figure 7a). In Model 2, eight hydrogen bonds were formed between RA and VmFbpA. Amino acid residues R9, G34, D35, T36, Q58, and Y196 were involved in the interaction (Figure $7 \mathrm{~b}$ ). In Model 3, seven hydrogen bonds were formed between RA and VmFbpA. Amino acid residues R9, Q58, G140, N193, Y195, and Y196 were involved in the interaction (Figure 7c). In Model 4, six hydrogen bonds were formed between RA and VmFbpA. Amino acid residues R9, N138, N193, and Y196 were involved in the interaction (Figure 7d). In Model 5, four hydrogen bonds were formed between RA and VmFbpA. Amino acid residues R9, Q58, and R100 were involved in the interaction (Figure 7e). In Model 6, six hydrogen bonds were formed between RA and VmFbpA. Amino acid residues R9, R100, Y196, and E262 were involved in the interaction (Figure 7f). In Model 7, six hydrogen bonds were formed between RA and VmFbpA. Amino acid residues Q58, Y195, and R199 were involved in the interaction (Figure 7g). In Model 8, four hydrogen bonds were formed between RA and VmFbpA. Amino acid residues Q58, N193, Y195, and E262 were involved in the interaction (Figure 7h). In Model 9, four hydrogen bonds were formed between RA and VmFbpA. Amino acid residues R9, Q58, N193, and E262 were involved in the interaction (Figure 7i).

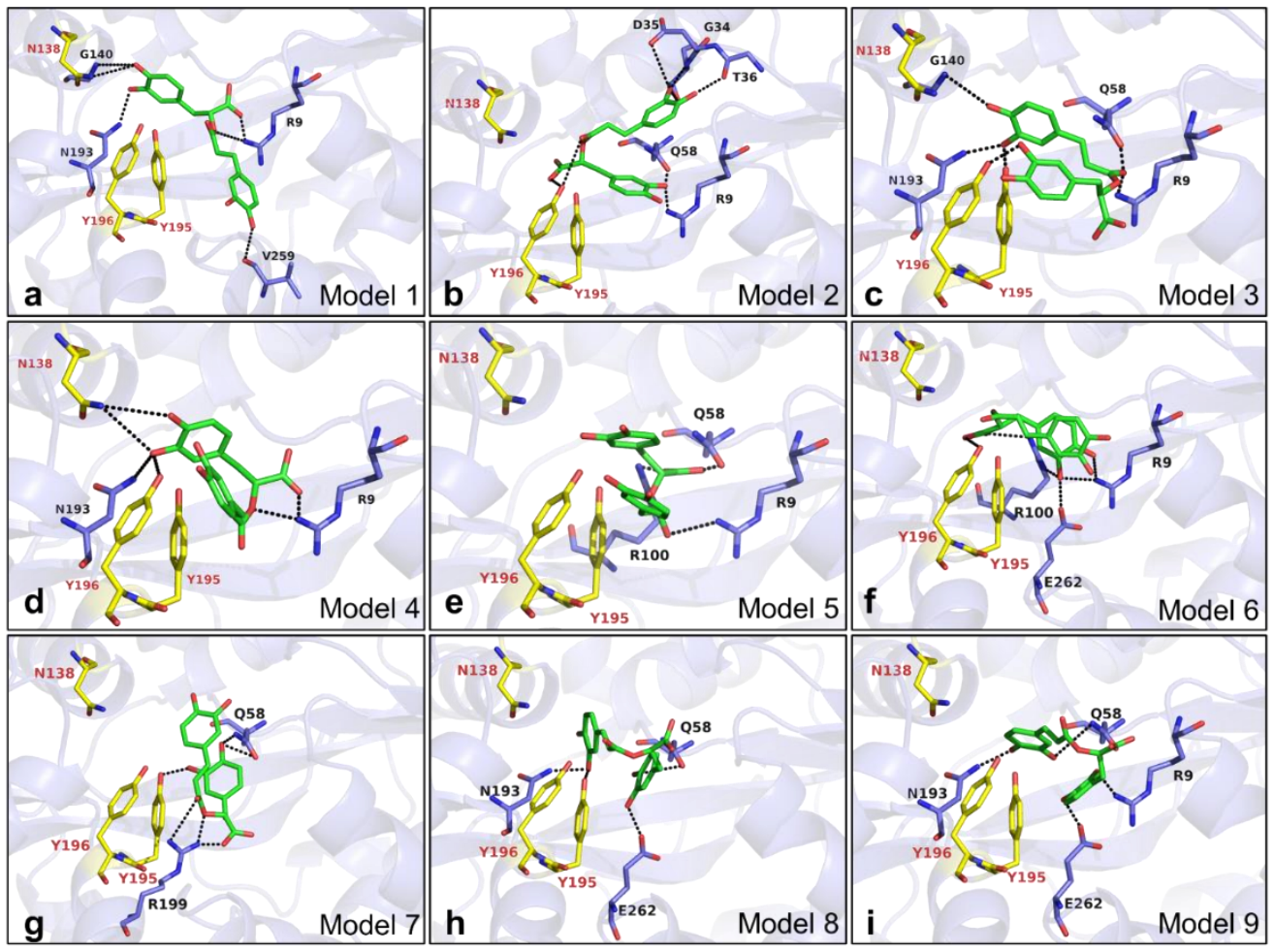

Figure 7. Docking results of RA binding to the $\mathrm{Fe}^{3+}$ binding site of $\mathrm{VmFbpA}$. (a-i) Docking models 1-9 after running docking simulation using AutoDock (version Vina 1.1.2). RA is shown as sticks in green. $\mathrm{Fe}^{3+}$ binding site of VmFbpA (N138, Y195, and Y196) shown as sticks in yellow. The amino acid residues predicted to form hydrogen bonds toward RA are shown as sticks in purple. The hydrogen bonds predicted by PDBePISA are shown as black dashed lines. VmFbpA is shown as a cartoon with a transparency of $60 \%$ and colored in purple.

\subsection{Inhibition by $R A$ and $S C$ of the Growth of $V$. vulnificus and V. parahaemolyticus}

To assess the bacteriostatic effects of RA and SC on other Vibrio species, $V$. parahaemolyticus (which causes the most Vibrio infections in the US) and V. vulnificus (which is the most lifethreatening non-cholera Vibrio bacterium), were used. V. vulnificus was almost completely inhibited by $100 \mathrm{mM}$ RA and $100 \mathrm{mM} \mathrm{SC}$, whereas $V$. parahaemolyticus was resistant to the 
same condition (Figure 8a). However, at 1000 mM RA, the growth of both $V$. vulnificus and $V$. parahaemolyticus was almost completely inhibited (Figure 8b).

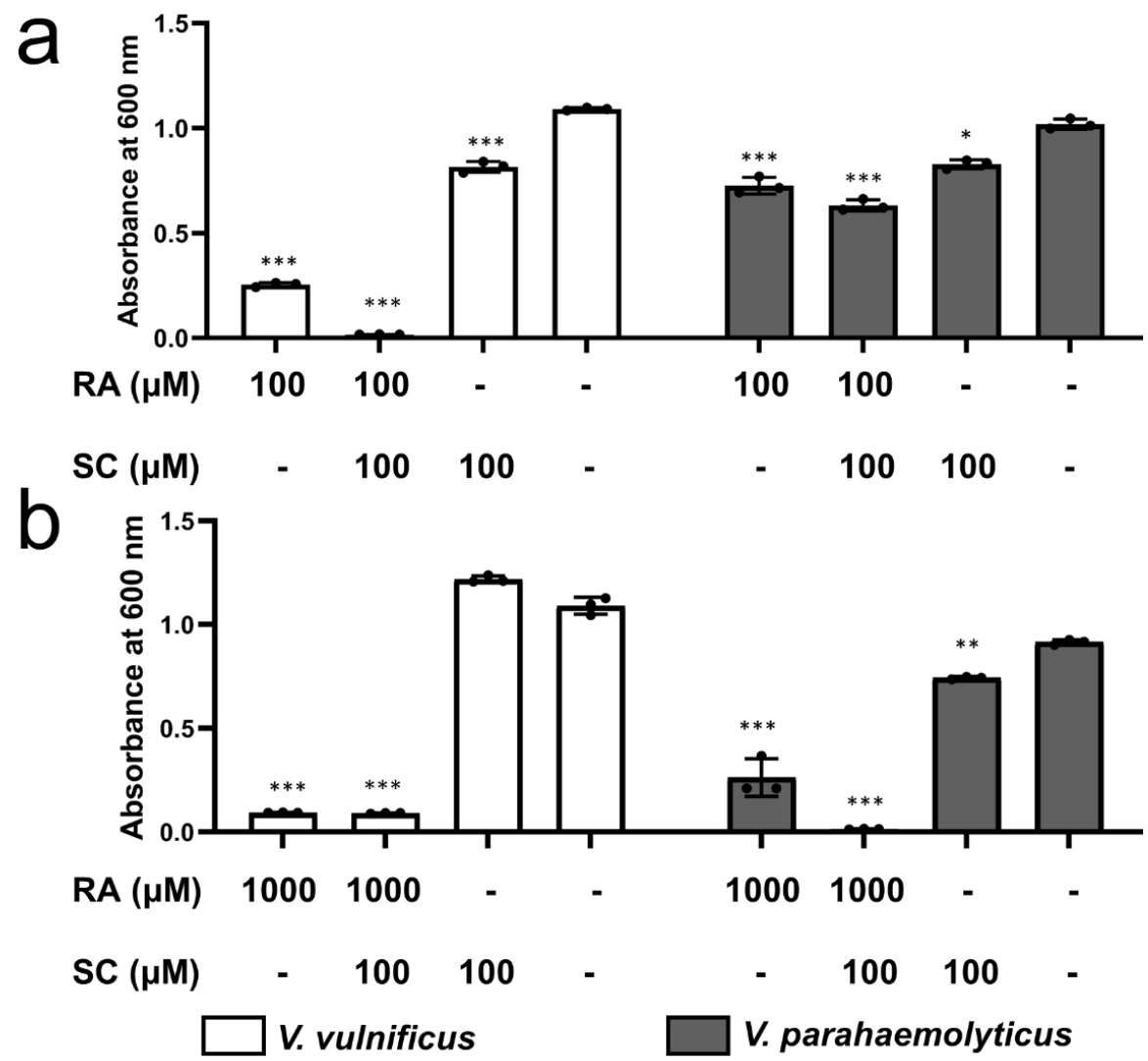

Figure 8. Antibacterial effects of RA and SC on V. vulnificus and V. parahaemolyticus. (a) Effect of $100 \mathrm{mM}$ RA with $100 \mathrm{mM}$ SC compared to RA and SC only. (b) Effect of $1000 \mathrm{mM}$ RA with $100 \mathrm{mM}$ SC compared to RA and SC only. The controls did not have exogenous chemicals added. ${ }^{*} p<0.05$, ** $p<0.01,{ }^{* * *} p<0.001$.

\section{Discussion}

\subsection{Screening and Identification of $R A$ as a VmFbpA Inhibitor}

Fe concentration was quantified via a $\mathrm{VmFbpA}$ inhibitor screening assay using ICPMS. Rosemary and cinnamon extracts decreased Fe concentrations to almost half of that in the Holo group ( $\mathrm{Fe}^{3+}-\mathrm{VmFbpA}$, positive control) (Figure 1a). UV-vis spectral analysis indicated a changed spectral pattern in samples treated with rosemary and cinnamon (Figure 1c,e). A significant peak shift (from $\approx 412$ to $\approx 380 \mathrm{~nm}$ ) in the UV-vis spectra was observed in samples treated with rosemary extracts (Figure 1e) but not in those treated with cinnamon extracts (Figure 1c). This indicates that the chemicals in the rosemary extracts interact with or bind to $\mathrm{VmFbpA}$. By contrast, the interaction between cinnamon extracts and $\mathrm{VmFbpA}$ may be nonspecific.

In rosemary, the most frequently reported functional chemical is RA, which is the main active phenolic compound and has antibacterial activity [16]. Consequently, a spectral analysis of apo $\mathrm{VmFbpA}$ supplemented with RA was performed (Figure 1f). The same peak shift (from $\approx 412$ to $\approx 380 \mathrm{~nm}$ ) as for rosemary extracts was observed. Therefore, the functional chemical that specifically interacts with $\mathrm{VmFbpA}$ was RA.

In the spectra of RA only (Figure $1 \mathrm{~g}$ ), no specific peak at $\approx 380 \mathrm{~nm}$ was observed. This demonstrated that the peak at $\approx 380 \mathrm{~nm}$ was a result of binding between VmFbpA and RA but not RA itself (Figure 1f,g). 


\subsection{Interaction between $R A$ and $V m F b p A$}

The ITC results demonstrated that the interaction between RA and apo VmFbpA takes place at a single site 1:1 binding with a $K_{\mathrm{D}}$ value of $8 \pm 1 \mu \mathrm{M}$ (Figure $3 \mathrm{a}$ ), which could be presented as below:

$$
\mathrm{RA}+\mathrm{VmFbpA} \rightleftharpoons \mathrm{RA} \cdot \mathrm{VmFbpA}(\text { Reaction } \mathrm{I}) .
$$

Based on the thermodynamic parameters obtained from the ITC results, $\Delta G$ for Reaction I at $298 \mathrm{~K}$ is $-5 \pm 2 \mathrm{kcal} / \mathrm{mol}$, indicating that Reaction I can progress spontaneously without external energy (Figure 3d). Furthermore, the $\Delta H$ and $-\mathrm{T} \Delta S$ for Reaction I were $-15 \pm 9 \mathrm{kcal} / \mathrm{mol}$ and $11 \pm 8 \mathrm{kcal} / \mathrm{mol}$, respectively, indicating that Reaction I was driven by enthalpy but not entropy and hydrogen bonds were the main interactions $[17,18]$ between RA and VmFbpA (Figure 3d).

The interaction between $\mathrm{RA}$ and $\mathrm{Fe}^{3+}-\mathrm{VmFbpA}$ was more complicated (Figure $3 \mathrm{~b}$ ). In the first four titrations, the heat change $(\mu \mathrm{cal} / \mathrm{s})$ experienced a decrease to a negative value (an exothermic reaction), which was followed by an increase to a positive value (an endothermic reaction), so that the net heat change was zero. An exothermic reaction was observed from the fifth to the eleventh titration, after which $\mathrm{VmFbpA}$ became saturated. The fact that an exothermic reaction followed by an endothermic reaction was observed in the first four titrations is a result of complex interactions among $\mathrm{Fe}^{3+}, \mathrm{VmFbpA}$, and RA. These interactions could include binding between RA and VmFbpA (exothermic reaction), binding between $\mathrm{Fe}^{3+}$ and $\mathrm{VmFbpA}$ (endothermic reaction) (Figure 3c) [19], and reduction of $\mathrm{Fe}^{3+}$ to $\mathrm{Fe}^{2+}$ by RA (Figure 2e). A significant heat difference was observed only when the molar ratio of RA: $\mathrm{Fe}^{3+}-\mathrm{VmFbpA}$ was higher than 2:1, indicating that RA binds to VmFbpA competitively at the $\mathrm{Fe}^{3+}$ binding site and $\mathrm{Fe}^{3+}-\mathrm{VmFbpA}$ has some resistance to RA at low concentrations.

Docking results showed that $\mathrm{RA}$ binds $\mathrm{VmFbpA}$ at the $\mathrm{Fe}^{3+}$ binding site $(\Delta \mathrm{G} \approx-7.0 \mathrm{kcal} / \mathrm{mol}$ ) (Figure S4d, Table S2) rather than the C-Lobe and N-Lobe $(\Delta \mathrm{G} \approx 0.0 \mathrm{kcal} / \mathrm{mol})$. The in silico theoretical $K_{\mathrm{D}}$ value between $\mathrm{RA}$ and apo $\mathrm{VmFbpA}$ is $\approx 7.1 \mu \mathrm{M}$ at room temperature, which is consistent with the in vitro ITC results. In the docking model, RA formed many hydrogen bonds with $\mathrm{VmFbpA}$ (Figure 7), indicating that the interaction between RA and $\mathrm{VmFbpA}$ is driven by enthalpy but not entropy, as described in the analysis of ITC results.

\subsection{Interaction between $R A$ and $F e^{3+}$}

The net spectra of RA in the presence of $\mathrm{Fe}^{3+}$ indicated that RA interacts with $\mathrm{Fe}^{3+}$ (Figure S3c), and the iron reduction experiments showed that RA can reduce $\mathrm{Fe}^{3+}$ to $\mathrm{Fe}^{2+}$ (Figure 2e,f). RA is an effective antioxidant, showing DPPH scavenging [20], ABTS(+) scavenging [21], and other activities. However, our results suggest that the antioxidant activity of RA is strong enough to reduce $\mathrm{Fe}^{3+}$ to $\mathrm{Fe}^{2+}$, which is consistent with a report that RA and its derivatives can reduce the $\mathrm{Fe}^{3+}$ in ferric 2,4,6-tris(2-pyridyl)-s-triazine (TPTZ) to $\mathrm{Fe}^{2+}$ to a colored product [22].

Therefore, $\mathrm{Fe}^{3+}$ release from VmFbpA by RA was in part caused by the competitive inhibition of $\mathrm{VmFbpA}$ and by the reduction of $\mathrm{Fe}^{3+}$ to $\mathrm{Fe}^{2+}$. The regression curve showed that $1 \mu \mathrm{M} \mathrm{RA}$ can reduce $\approx 2.44 \mu \mathrm{M} \mathrm{Fe}^{3+}$ to $\mathrm{Fe}^{2+}$ (Figure $2 \mathrm{f}$ ), indicating that the stoichiometry of the reaction between $\mathrm{RA}$ and $\mathrm{Fe}^{3+}$ is approximately 1:2 and one RA molecule can reduce about two $\mathrm{Fe}^{3+}$ to $\mathrm{Fe}^{2+}$ (Figure 2f).

\subsection{Inhibition of V. metschnikovii Growth by RA}

The growth of $V$. metschnikovii was significantly inhibited by RA in a dose-dependent manner (Figure 4a). This is probably because the iron-capturing protein, $\mathrm{VmFbpA}$, was inhibited by RA (Figure 2c,d), and Fe utilization in V. metschnikovii is significantly lowered (Figure 5b). The recovery experiments showed that the bactericidal activity of RA 
against $V$. metschnikovii resulted from the restriction of iron uptake, because the growth of $V$. metschnikovii was recovered after adding $5 \mu^{\mathrm{mol} \mathrm{FeCl}} 3$ (Figure $5 \mathrm{c}, \mathrm{d}$ ).

E. coli is the most abundant bacterium in the human colon. Therefore, we evaluated the growth of E. coli with the supplementation of RA. E. coli was not significantly inhibited by RA (Figure $4 \mathrm{c}, \mathrm{d}$ ). Similarly, it has been reported that $E$. coli is more resistant to rosemary extracts and RA than other Gram-negative bacteria [16]. Moreover, E. coli can use a wide range of iron sources, for instance, ferric ammonium citrate, hematin hydrochloride, lysed guinea-pig red cells, crystalline human hemoglobin [23], and ferrous ion [24]. Therefore, even if $\mathrm{FbpA}$, the $\mathrm{Fe}^{3+}$ capturing protein, is inhibited, E. coli could use other iron sources for growth (Table 1).

Table 1. Comparison of transporters involved in the uptake of different iron sources.

\begin{tabular}{|c|c|c|}
\hline & E. coli & V. metschnikovii \\
\hline $\mathrm{Fe}^{3+}$ & $\mathrm{FbpBC} / \mathrm{A}[25]$ & $\mathrm{FbpBC} / \mathrm{A}^{\mathrm{a}}$ \\
\hline $\mathrm{Fe}^{3+}$-siderophore & $\begin{array}{c}\text { FhuBC /D ( } \mathrm{Fe}^{3+} \text {-hydroxamate) [26] } \\
\text { FepABC (Fe } \mathrm{Fe}^{3+} \text {-enterobactin) [26] } \\
\text { IutA }\left(\mathrm{Fe}^{3+} \text {-aerobactin) [26] }\right. \\
\text { FyuA (Fe } \mathrm{Fe}^{3+} \text {-yersiniabactin) [26] } \\
\text { FeoABC } 27]\end{array}$ & CeuBC/A ( $\mathrm{Fe}^{3+}$-enterochelin $)^{\mathrm{a}}$ \\
\hline $\mathrm{Fe}^{2+}$ & $\begin{array}{c}\text { EfeOUB [24] } \\
\text { MntH [28] }\end{array}$ & FeoABC $^{\mathrm{a}}$ \\
\hline Fe-citrate & $\mathrm{Fec}(\mathrm{CD}) \mathrm{E} / \mathrm{B}[29]$ & N.A. \\
\hline
\end{tabular}

Additionally, it is important to note that the $\mathrm{pH}$ of the NB medium did not change significantly after adding RA and SC (Figure S7). Therefore, it is not the $\mathrm{pH}$ change that affects the growth of bacteria.

\subsection{Effect of RA Combined with SC on Bacterial Growth}

RA $(1000 \mu \mathrm{M})$ inhibited the growth of $V$. metschnikovii to $\approx 65 \%$ (Figure $4 \mathrm{a}, \mathrm{b})$, and the inhibition was enhanced to $>90 \%$ by adding SC (Figure $6 a, b$ ). However, RA did not significantly inhibit $E$. coli growth (Figure 4c,d), nor did the combination of RA and SC (Figure $6 c, d)$. These results indicate that $E$. coli uses a variety of iron sources and is resistant to RA and SC, but $V$. metschnikovii is more vulnerable to RA in the presence of SC. E. coli and $V$. metschnikovii have an $\mathrm{FbpBC} / \mathrm{A}$ uptake system to take up $\mathrm{Fe}^{3+}$, which is a common means of absorbing iron (Table 1). Under anaerobic, low $\mathrm{pH}$, or reducing conditions, iron is mainly present as $\mathrm{Fe}^{2+}$ [25]. E. coli has evolved diverse transporter systems (FeoABC [27], EfeOUB [24], and MntH [28]) to absorb $\mathrm{Fe}^{2+}$, whereas V. metschnikovii has only an FeoABC system (Table 1).

Interestingly, E. coli responds to iron restriction by producing citrate $[30,31]$ and has an Fec(CD)E/A transporter system for ferric citrate uptake [29], which is absent in $V$. metschnikovii (Table 1). Furthermore, FecB, the periplasmic subunit of the $\mathrm{Fec}(\mathrm{CD}) \mathrm{E} / \mathrm{B}$ system, binds a variety of Fe-citrate complexes (citrate, $\mathrm{Fe}^{3+}-\mathrm{Cit},\left[\mathrm{Fe}_{2}\left(\mathrm{Cit}_{2}\right)\right]^{2-}$, and $\left[\mathrm{Fe}(\mathrm{Cit})_{2}\right]^{5-}$ ) as well as other citrate complexes $\left(\mathrm{Ga}^{3+}, \mathrm{Al}^{3+}, \mathrm{Sc}^{3+}, \mathrm{In}^{3+}\right.$, and $\left.\mathrm{Mg}^{2+}\right)$ with a $K_{\mathrm{d}}$ value in the micromolar range [29]. When FbpAs in E. coli and V. metschnikovii were inhibited by $1000 \mu \mathrm{M}$ RA, $\mathrm{Fe}^{3+}$ was reduced to $\mathrm{Fe}^{2+}$. Subsequently, adding citrate chelates free $\mathrm{Fe}^{2+}$ into $\mathrm{Fe}^{2+}$-citrate complexes. These $\mathrm{Fe}^{2+}$-citrate complexes can be taken up by $E$. coli via the $\mathrm{Fec}(\mathrm{CD}) \mathrm{E} / \mathrm{B}$ transporter system, whereas the $\mathrm{Fe}^{2+}$-citrate complexes are not bioavailable for $V$. metschnikovii. This could be why E. coli is more resistant to RA and the combination of RA and SC than $V$. metschnikovii. Therefore, RA combined with SC could inhibit $V$. metschnikovii without deleterious effects on indigenous gastrointestinal bacteria.

Moreover, the following reasons may explain why SC did not affect the growth of $V$. metschnikovii. SC chelates $\mathrm{Fe}^{3+}$ to $\mathrm{Fe}^{3+}$-citrate complexes, but $V$. metschnikovii has a siderophore-based CeuBC/A transporter that is responsible for $\mathrm{Fe}^{3+}$-enterochelin uptake 
(Table 1). V. metschnikovii releases the siderophore enterochelin to absorb $\mathrm{Fe}^{3+}$ under ironrestricted conditions. Enterochelin is the strongest siderophore and binds to $\mathrm{Fe}^{3+}$ with extremely strong affinity $\left(\mathrm{Ka}=10^{52} \mathrm{M}^{-1}\right)$ [32]. This value is substantially higher than even several synthetic metal chelators, such as EDTA $\left(\mathrm{Ka}=10^{25} \mathrm{M}^{-1}\right)$ [33]. Therefore, without $\mathrm{RA}, \mathrm{Fe}^{3+}$ was not reduced to $\mathrm{Fe}^{2+}$. If $\mathrm{Fe}^{3+}$ is chelated by citrate, it can be reclaimed by enterochelin. This explains why the growth of $V$. metschnikovii was not affected by SC alone.

Considering the future potential applications of $\mathrm{VmFbpA}$ inhibitors, we conducted an alignment of $\mathrm{VmFbpA}$ to other FbpAs from pathogenic Vibrio species. Since we focused on non-cholera Vibrio infections in this study, V. vulnificus and V. parahaemolyticus were selected for the further antibacterial experiments. The results showed that FbpA is a highly conserved protein with a sequence identity of $\approx 31 \%$ (Figure S6, Table S4). Bacteriostatic experiments (Figure 5) on V.vulnificus and V. parahaemolyticus indicated that RA combined with SC can also inhibit the growth of these infectious Vibrio by limiting $\mathrm{Fe}^{3+}$ uptake. Based on the knowledge iron uptake proteins in Vibrio bacteria, the RA/SC would be further effective in suppressing the growth of $V$. cholerae, although it needs to be confirmed.

Additionally, the results from a pilot experiment performed in Japan several decades ago support our experimental data [34]. The traditional Japanese food "umeboshi" is made with shiso (perilla; Perilla frutescens var. crispa) and ume (salted Japanese plum; Prunus mume Sieb. et Zucc.), which contain RA and SC, respectively. Due to its antibacterial properties, umeboshi was traditionally used as a medicine in the middle and early modern ages and is currently used as a natural preservative to prevent the spoilage of items in lunch boxes and rice balls. In the 19th and early 20th centuries, umeboshi was found to be an effective treatment for cholera and was used as an anti-cholera medicine in Japan. Tetsumoto (1934) found that umeboshi exhibited strong bactericidal activity against $V$. cholerae, as compared to citric acid, which has a similar $\mathrm{pH}$ [34]. Our data presented here suggest that RA and SC are among the anti-cholera components in umeboshi. Here, we propose that the anti-cholera activity of umeboshi could be exerted mainly or partly by inhibiting the iron uptake by $V$. cholerae, although it needs to be confirmed by further experiments.

\section{Materials and Methods}

\subsection{Chemicals and Materials}

RA (98\% pure, CAS: 20283-92-5) was purchased from Combi-Blocks (San Diego, CA, USA). All other reagents used in this study were purchased from Fujifilm Wako Pure Chemical Co., Ltd. (Osaka, Japan) unless otherwise stated.

Twenty spices, including Sanshō (Zanthoxylum piperitum), oregano (Origanum vulgare), thyme (Thymus vulgaris), allspice (Pimenta dioica), rosemary (Salvia rosmarinus), basil (Ocimum basilicum), coriander (Coriandrum sativum), parsley (Petroselinum crispum), cumin (Cuminum cyminum), cumin seeds, ginger (Zingiber officinale), cinnamon (Cinnamomum verum), paprika (Capsicum annuum), garam masala, garlic (Allium sativum), nutmeg (Myristica fragrans), turmeric (Curcuma longa), chili pepper (Capsicum annuum), black pepper (Piper nigrum), and white pepper (Piper nigrum) used were the products of S\&B Foods (Tokyo, Japan).

Vibrio species (V. metschnikovii, V. vulnificus, and V. parahaemolyticus) were obtained from Japan Collection of Microorganisms, RIKEN (Ibaraki, Japan) and were handled in a safety cabinet to avoid contamination. All E. coli strains (BL21(DE3) and KRX) were purchased from Novagen (Madison, WI, USA) and Promega (Madison, WI, USA), respectively, and were handled in a clean bench to avoid contamination.

\subsection{Aqueous Extracts of Spices}

A total of $0.50 \mathrm{~g}( \pm 0.01)$ of each spice was ground into powder, extracted in $20 \mathrm{~mL}$ boiling Milli-Q (Milli-Q Advantage), and incubated in a water bath at $95^{\circ} \mathrm{C}$ for $3 \mathrm{~h}$. The insoluble fraction was removed using a $0.45 \mu \mathrm{m}$ polyethersulfone (PES) filter. The filtrate was evaporated to powder and stored at $-30^{\circ} \mathrm{C}$. 


\subsection{Expression and Purification of $6 \times$ His-tev-VmFbpA}

The gene encoding VmFbpA (WP_004394209.1) without the signal peptide 'MQKKLLSTVALVSSLITAPLLHA' was cloned into a modified pET-28a vector, where the thrombin cleavage site had been replaced by a TEV cleavage site, and overexpressed in E. coli BL21(DE3). Large-scale overexpression of $6 \times$ His-tev-VmFbpA was performed at $30^{\circ} \mathrm{C}$ in $2 \mathrm{~L}$ of LB medium with isopropyl $\beta$-D-1-thiogalactopyranoside (final concentration $0.001 \mathrm{mM})$ at an $\mathrm{OD}_{600}$ of about 0.6 . After the induction, the cells were cultivated at $30{ }^{\circ} \mathrm{C}$ for $20 \mathrm{~h}$ and harvested by centrifugation at $4000 \times \mathrm{g}$ and $4{ }^{\circ} \mathrm{C}$ for $20 \mathrm{~min}$. The cells were suspended in lysis buffer (20 mM Tris- $\mathrm{HCl}$ (pH 8.0), $100 \mathrm{mM} \mathrm{NaCl}, 10 \mathrm{mM}$ imidazole, $0.50 \mathrm{mg} / \mathrm{mL}$ lysozyme, and $1.2 \mathrm{U} / \mathrm{mL}$ DNase I). Subsequently, the cells were disrupted by sonication using $70 \%$ amplitude, $0.5 \mathrm{~s}$ on/off, for $7 \mathrm{~min}$, and the resulting cell lysate was centrifuged at $40,000 \times g$ and $4{ }^{\circ} \mathrm{C}$ for $30 \mathrm{~min}$. The supernatant was loaded onto a Ni-nitrilotriacetic acid (Ni-NTA) column (bed volume $2 \mathrm{~mL}$ ), washed and eluted sequentially by wash buffer 1 (20 mM Tris- $\mathrm{HCl}$ (pH 8.0), $100 \mathrm{mM} \mathrm{NaCl}$, and $10 \mathrm{mM}$ imidazole), wash buffer 2 (wash buffer 1 supplemented with $20 \mathrm{mM}$ imidazole), elution buffer 1 (wash buffer 1 with $50 \mathrm{mM}$ imidazole), elution buffer 2 (wash buffer 1 with $100 \mathrm{mM}$ imidazole), elution buffer 3 (wash buffer 1 with $150 \mathrm{mM}$ imidazole), and elution buffer 4 (wash buffer 1 with $250 \mathrm{mM}$ imidazole). Based on the sodium dodecyl sulfate-polyacrylamide gel electrophoresis (SDS-PAGE) data, all fractions containing $6 \times$ His-tev-VmFbpA were collected and stored at $4{ }^{\circ} \mathrm{C}$ before use.

\subsection{Preparation of $6 \times$ His-tag-free VmFbpA}

A total of $6 \times$ His-tev-VmFbpA were dialyzed overnight against lysis buffer at $4{ }^{\circ} \mathrm{C}$ to lower the imidazole concentration. The $6 \times$ His-tag was cleaved by adding $6 \times$ His-TEV protease (homemade, 10 units $/ \mathrm{mg}$ protein). Then, the reaction mixture was reloaded on the Ni-NTA column and the eluent, which contained mainly $6 \times$ His-tag-free VmFbpA, and was collected and concentrated with a Vivaspin 20 (MWCO $10 \mathrm{~K}$, Sartorius) to a protein concentration of approximately $1.5 \mathrm{mg} / \mathrm{mL}$. Then, the sample was loaded onto a Superdex 200 10/300 GL column (GE Healthcare) and separated using gel filtration buffer A ( $20 \mathrm{mM}$ Tris- $\mathrm{HCl}(\mathrm{pH}$ 8.0) and $100 \mathrm{mM} \mathrm{NaCl}$ ) using an ÄKTA purifier (GE Healthcare) for the final purification. Protein samples were adjusted to a final protein concentration of $0.3 \mathrm{mM}$ by ultrafiltration using a Vivaspin 20 (MWCO $10 \mathrm{~K}$, Sartorius) and stored at $4{ }^{\circ} \mathrm{C}$.

\subsection{Preparation of $\mathrm{Fe}^{3+}-\mathrm{VmFbpA}$ and Apo VmFbpA}

To form $\mathrm{Fe}^{3+}$-bound $\mathrm{VmFbpA}$, ferric chloride hexahydrate $\left(\mathrm{FeCl}_{3} \cdot 6 \mathrm{H}_{2} \mathrm{O}\right)$ was added to purified $\mathrm{VmFbpA}$ to a final concentration of $4.2 \mathrm{mM}$. Next, EDTA at a final concentration of $10 \mathrm{mM}$ was added to form apo $\mathrm{VmFbpA}$. The samples were incubated with $50 \mathrm{mM}$ sodium bicarbonate $\left(\mathrm{NaHCO}_{3}\right)$ at $4{ }^{\circ} \mathrm{C}$ for $20 \mathrm{~h}$ and then concentrated to a protein concentration of approximately $0.7 \mathrm{mg} / \mathrm{mL}$. Each sample was loaded onto a Superdex 200 10/300 GL column and separated using gel filtration buffer $\left(50 \mathrm{mM}\right.$ Tris- $\mathrm{HCl}(\mathrm{pH} 8.0), 50 \mathrm{mM} \mathrm{NaHCO}_{3}$, and $150 \mathrm{mM} \mathrm{NaCl}$ ). Fractions were collected according to the peak measured at $280 \mathrm{~nm}$. The samples were adjusted to a final protein concentration of $0.1 \mathrm{mM}$ by ultrafiltration using a Vivaspin 20 (MWCO $10 \mathrm{~K}$ ) and stored at $4{ }^{\circ} \mathrm{C}$.

\subsection{Six $\times$ His-based VmFbpA Inhibition Assay (Pull-Down Assay)}

Two-hundred microliters of $0.3 \mathrm{mM}$ apo $6 \times$ His-tev-VmFbpA were loaded onto a $40 \mu \mathrm{L}$ Ni-NTA slurry resin (bed volume: $20 \mu \mathrm{L}$ ) in a Micro Bio-Spin column (Bio-Rad) and incubated at $4{ }^{\circ} \mathrm{C}$ for $30 \mathrm{~min}$ with $3.0 \mathrm{mM} \mathrm{FeCl}_{3}$. The column was extensively washed with washing buffer (50 mM Tris- $\mathrm{HCl}(\mathrm{pH} 8.0), 50 \mathrm{mM} \mathrm{NaHCO}_{3}, 150 \mathrm{mM} \mathrm{NaCl}$, and $20 \mathrm{mM}$ imidazole). Spice extract or RA $(200 \mu \mathrm{L})$ was loaded onto the column and incubated at $4{ }^{\circ} \mathrm{C}$ for $60 \mathrm{~min}$. The solvent for spice extracts and RA was $50 \mathrm{mM}$ Tris- $\mathrm{HCl}(\mathrm{pH} 8.0), 50 \mathrm{mM}$ $\mathrm{NaHCO}_{3}$, and $150 \mathrm{mM} \mathrm{NaCl}$. The column was subsequently washed extensively with washing buffer ( $50 \mathrm{mM}$ Tris- $\mathrm{HCl}(\mathrm{pH} 8.0), 50 \mathrm{mM} \mathrm{NaHCO}{ }_{3}, 150 \mathrm{mM} \mathrm{NaCl}$, and $20 \mathrm{mM}$ imidazole) and eluted with $300 \mu \mathrm{L}$ elution buffer ( $50 \mathrm{mM}$ Tris- $\mathrm{HCl}$ ( $\mathrm{pH} 8.0), 50 \mathrm{mM} \mathrm{NaHCO}$, 
$150 \mathrm{mM} \mathrm{NaCl}$, and $250 \mathrm{mM}$ imidazole). The Fe concentration of eluent was determined by ICP-MS as reported previously [19] and adjusted to the protein concentration (measured using a Pierce $660 \mathrm{~nm}$ Protein Assay, Thermo Fisher Scientific) in the eluent. Samples without $\mathrm{FeCl}_{3}$ were used as the negative control group, and samples lacking rosemary extract or RA as the positive control group. Unless indicated, all buffers contained $0.3 \%$ dimethyl sulfoxide (DMSO) [35] to solubilize RA.

\subsection{Determination of the $50 \%$ Inhibitory Concentration}

Rosemary extracts and RA were used to evaluate $\mathrm{VmFbpA}$ inhibitory activity. Twohundred microliters of rosemary extracts $(1.56$ to $25.0 \mathrm{mg} / \mathrm{mL})$ and $\mathrm{RA}(2.34 \mu \mathrm{g} / \mathrm{mL}$ to $2.40 \mathrm{mg} / \mathrm{mL}$ ), with a two-fold dilution gradient were performed. Apo VmFbpA was used as the negative control and $\mathrm{Fe}^{3+}-\mathrm{VmFbpA}$ lacking RA was used as the positive control. The Fe concentration of the eluents was determined by ICP-MS as reported previously [19]. The inhibitory rates were calculated as below:

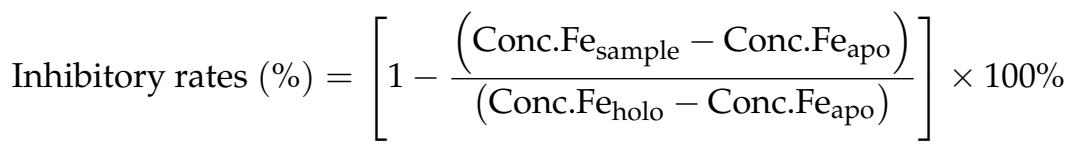

The inhibitory rate was plotted in a scatter plot as a function of RA concentration and fitted by a logarithmic function model. The $50 \%$ inhibitory concentration $\left(\mathrm{IC}_{50}\right)$ was calculated by reading the RA concentration at the inhibitory rate is $50 \%$.

\subsection{Spectral Analysis of VmFbpA Interacting with Rosemary Extracts and $R A$}

Rosemary extracts ( 15 to $0.9 \mathrm{mg} / \mathrm{mL}$, with a two-fold dilution gradient) and $200 \mu \mathrm{L}$ $0.3 \mathrm{mM}$ apo $6 \times$ His-tev-VmFbpA with $3 \mathrm{mM} \mathrm{FeCl}_{3}$ were used in a pull-down assay to assess the interaction between $\mathrm{Fe}^{3+}-\mathrm{VmFbpA}$ and RA.

RA ( 2.4 to $0.15 \mathrm{mg} / \mathrm{mL}$, with a two-fold dilution gradient) and $200 \mu \mathrm{L} 0.3 \mathrm{mM}$ apo $6 \times$ His-tev-VmFbpA without $\mathrm{FeCl}_{3}$ were used in the pull-down assay to assess the interaction between apo VmFbpA and RA.

The absorbance spectra of the eluents at $300-700 \mathrm{~nm}$ were measured using a UV-vis spectrophotometer (JASCO V-630) at room temperature. Samples without $\mathrm{FeCl}_{3}$ and RA were used as the negative controls and samples lacking RA were used as the positive control. Samples without preloading of apo $6 \times$ His-tev- $\mathrm{VmFbpA}$ were used to determine the background.

\subsection{Spectral Analysis of RA Interacting with $\mathrm{Fe}^{3+}$}

Solutions of $20 \mu \mathrm{M}$ RA supplemented with $0,10,20,30$, and $40 \mu \mathrm{M} \mathrm{FeCl}_{3}$ were used for UV-vis spectra analysis. The absorbance at $200-700 \mathrm{~nm}$ was measured using a UV-vis spectrophotometer (Jasco V-630) at room temperature. Solutions of 0, 10, 20, 30, and $40 \mu \mathrm{M}$ $\mathrm{FeCl}_{3}$ without $20 \mu \mathrm{M}$ RA were used as the controls. The buffers did not contain DMSO.

\subsection{Analysis of RA on $\mathrm{Fe}^{3+}$ Reduction}

Solutions of $40 \mu \mathrm{M} \mathrm{FeCl}_{3}$ supplemented with $0,0.625,1.25,5,10,20$, and $40 \mu \mathrm{M}$ RA were used for analysis. First, $0.25 \%$ o-phenanthroline $(2 \mathrm{~mL})$ was added to each sample, and the $\mathrm{pH}$ was adjusted to 3.5 with hydrochloric acid $(\mathrm{HCl})$. Milli-Q water was added to a final volume of $25 \mathrm{~mL}$. After $1 \mathrm{~h}$ incubation, the absorbance at $510 \mathrm{~nm}$ was measured using a microplate spectrophotometer (Benchmark Plus, Bio-Rad). The concentration of $\mathrm{Fe}^{2+}$ was quantified using ferrous sulfate heptahydrate $\left(\mathrm{FeSO}_{4} \cdot 7 \mathrm{H}_{2} \mathrm{O}\right)$ as the standard. The buffers did not contain DMSO.

\subsection{ITC Analysis}

The $6 \times$ His-free apo $/ \mathrm{Fe}^{3+} \mathrm{VmFbpA}$ samples were dialyzed overnight at $4{ }^{\circ} \mathrm{C}$ against dialysis buffer ( $20 \mathrm{mM}$ Tris- $\mathrm{HCl}$ (pH 8.0), $25 \mathrm{mM} \mathrm{NaHCO}_{3}$, and $50 \mathrm{mM} \mathrm{NaCl}, 20 \mathrm{mM}$ imida- 
zole, $0.3 \%$ DMSO). ITC was performed using MicroCal iTC200 (Malvern). RA (0.5 mM) or $\mathrm{Fe}^{3+}(0.1 \mathrm{mM})$ diluted in dialysis buffer was injected 20 times by a motor-driven syringe into $200 \mu \mathrm{L} 0.01 \mathrm{mM}$ Apo VmFbpA. The first injection volume was $0.1 \mu \mathrm{L}$, and the subsequent injection volumes were $2.0 \mu \mathrm{L}$. The solution in the titration cell was stirred at $750 \mathrm{rpm}$ throughout the experiment. In addition, titration of RA $(0.5 \mathrm{mM})$ into $\mathrm{Fe}^{3+}-\mathrm{VmFbpA}(0.1 \mathrm{mM})$ was performed as described above. The reference cell of the microcalorimeter was filled with $200 \mu \mathrm{L}$ of the corresponding dialysis buffer. The titrations were performed at room temperature. The data were analyzed by MicroCal LLC iTC 200 for Windows (Malvern).

\subsection{Crystallization and X-ray Diffraction Data Collection}

Initial crystallization screening was performed in 96-well Violamo Protein Crystallization Plates (As One) using commercially available kits, namely Crystal Screen HT, Index HT (Hampton Research), and Wizard I and II (Emerald BioSystems) at 293 K. A crystallization drop was prepared by mixing $0.5 \mu \mathrm{L}$ protein solution and $0.5 \mu \mathrm{L}$ reservoir solution and was equilibrated against $40 \mu \mathrm{L}$ reservoir solution. After two-dimensional grid optimization of the crystallization conditions ( $\mathrm{pH}$ versus precipitant concentration), they were further optimized by the sitting-drop vapor-diffusion method in 24-well Cryschem Plates (Hampton Research). A crystallization drop was prepared by mixing $1.0 \mu \mathrm{L}$ protein solution and $1.0 \mu \mathrm{L}$ reservoir solution and was equilibrated against $500 \mu \mathrm{L}$ reservoir solution.

Crystals of apo VmFbpA were obtained using a reservoir composition of $0.25 \mathrm{M}$ ammonium tartrate dibasic, 25\% PEG3350, $100 \mathrm{mM}$ Tris- $\mathrm{HCl}$ (pH 7.0). Each crystal was picked up in a mounting loop and cooled in a cold nitrogen-gas stream using a cryoprotectant consisting of $0.25 \mathrm{M}$ ammonium tartrate dibasic, 25\% PEG3350, $100 \mathrm{mM}$ Tris- $\mathrm{HCl}$ (pH 7.0), and $20 \%(v / v)$ glycerol. X-ray diffraction experiments for apo $\mathrm{VmFbpA}$ crystals were performed on beamlines BL44XU at SPring-8 (Hyogo, Japan) and AR-NE3A at Photon Factory (Ibaraki, Japan). The final data set was collected from an apo VmFbpA crystal at a wavelength of $0.899995 \AA$, a crystal-to-detector distance of $319.90 \mathrm{~mm}$, an oscillation angle of $0.1^{\circ}$, and an exposure time of $0.1 \mathrm{~s}$ per image using an EIGER $16 \mathrm{M}$ detector at BL44XU at SPring-8. The structure solution and refinement were described in the Supplementary Information.

\subsection{Docking Simulation}

The crystal structure of apo VmFpbA solved in this study was used as the template. Docking simulation analysis was performed on a Linux (CentOS 7.0) platform using AutoDock (version Vina 1.1.2) [36]. Three areas were selected (N-terminus, C-terminus, and the $\mathrm{Fe}^{3+}$-binding site) (Figure S5a) as the docking cavities for the grid box to cover. The 3D model of RA (Figure S5b) was created by ChemBioDraw Ultra (version 13.0.0.3015) and optimized by AutoDockTools (version 1.5.4). The default mode was used.

\subsection{Inhibition by RA of V. metschnikovii Growth}

The glycerol stock of $V$. metschnikovii was prepared by culturing the bacteria in NB liquid medium (meat extract $3.0 \mathrm{~g} / \mathrm{L}$, meat peptone $5.0 \mathrm{~g} / \mathrm{L}, \mathrm{NaCl} 10.0 \mathrm{~g} / \mathrm{L}$, at pH 7.0) and flash freezing in liquid nitrogen after adding $50 \%$ glycerol $(1: 1, v / v)$ at the $\mathrm{OD}_{600}$ of 0.6. Next, $10 \mu \mathrm{L} V$. metschnikovii cell from the glycerol stock were added to $10 \mathrm{~mL}$ NB medium containing $0.3 \%$ DMSO and 1000, 500, 100, 50, 25, and $0 \mu \mathrm{M}$ RA. The culture was performed at $37^{\circ} \mathrm{C}$. The optical density at $600 \mathrm{~nm}$ was monitored every $\mathrm{h}(0-10 \mathrm{~h})$ by a microplate spectrophotometer (Benchmark Plus, Bio-Rad).

\subsection{Inhibition of E. coli Growth by RA}

A glycerol stock of E. coli (BL21(DE3) or KRX) was prepared by culturing the bacteria in NB medium and flash freezing in liquid nitrogen after adding $50 \%$ glycerol $(1: 1, v / v)$ to an $\mathrm{OD}_{600}$ of 0.6. E. coli (BL21(DE3) or KRX) $(10 \mu \mathrm{L})$ from the glycerol stock was added to $10 \mathrm{~mL} \mathrm{NB}$ medium containing 0.3\% DMSO and 1000, 500, 100, 50, 25, and $0 \mu \mathrm{M} \mathrm{RA}$. The culture was performed at $37^{\circ} \mathrm{C}$. The optical density at $600 \mathrm{~nm}$ was monitored every hour (0-10 h) by a microplate spectrophotometer (Benchmark Plus, Bio-Rad). 


\subsection{Measurement of Iron Utilization by V. metschnikovii}

$V$. metschnikovii $(10 \mu \mathrm{L})$ from the glycerol stock were added to $10 \mathrm{~mL}$ NB medium containing $0.3 \%$ DMSO and 1000, 500, 100, 50, 25, and $0 \mu \mathrm{M}$ RA. The culture was performed at $37^{\circ} \mathrm{C}$ for $7 \mathrm{~h}$ followed by centrifugation at $40,000 \mathrm{~g}$ for $15 \mathrm{~min}$. The weight of precipitate (V. metschnikovii) was measured using a precision balance. The remaining iron in supernatant was measured using ICP-MS as reported previously [19]. The Fe utilization ratio was calculated as:

$$
\text { Fe utilization ratio }\left(\mu \mathrm{mol} \cdot \mathrm{L}^{-1} \cdot \mathrm{g}^{-1}\right)=\frac{\mathrm{Fe}_{\mathrm{Conc}, \mathrm{BK}}-\mathrm{Fe}_{\mathrm{Conc}, \text { Remian }}}{\mathrm{m}_{\text {vibrio }} \times \mathrm{V}}
$$

where $\mathrm{Fe}_{\mathrm{Conc}, \mathrm{BK}}$ is the original iron concentration in NB medium, $\mathrm{Fe}_{\mathrm{Con}, \mathrm{Remain}}$ is the remaining iron concentration after culture of $V$. metschnikovii, $\mathrm{m}_{\text {vibrio }}$ is the weight of $V$. metschnikovii after culture, and $\mathrm{V}$ is the volume of NB medium.

\subsection{Recovery of V. metschnikovii by Supplementation of $\mathrm{Fe}^{3+}$}

$V$. metschnikovii $(10 \mu \mathrm{L})$ from the glycerol stock was added to $10 \mathrm{~mL}$ NB medium containing $1000 \mu \mathrm{M}$ RA with 10 and $50 \mu \mathrm{mol} \mathrm{FeCl} 3$, respectively. The positive control group was $V$. metschnikovii without supplementation of $\mathrm{RA}$ and $\mathrm{FeCl}_{3}$. The negative control group was $V$. metschnikovii without $\mathrm{FeCl}_{3}$. Culture was performed at $37^{\circ} \mathrm{C}$. The optical density at $600 \mathrm{~nm}$ was monitored every hour $(0-10 \mathrm{~h})$ by a microplate spectrophotometer (Benchmark Plus, Bio-Rad).

\subsection{Inhibition by RA and SC of the Growth of V. metschnikovii}

$V$. metschnikovii $(10 \mu \mathrm{L})$ from the glycerol stock was added to $10 \mathrm{~mL}$ of NB medium supplemented with RA and SC. Culture was performed at $37^{\circ} \mathrm{C}$ for $7 \mathrm{~h}$. Optical density at $600 \mathrm{~nm}$ was measured using a microplate spectrophotometer (Benchmark Plus, Bio-Rad).

\subsection{Inhibition by RA and SC of the Growth of E. coli}

E. coli (BL21(DE3) or KRX) $(10 \mu \mathrm{L})$ from the glycerol stock was added to $10 \mathrm{~mL}$ NB medium supplemented with RA and SC. Culture was performed at $37^{\circ} \mathrm{C}$ for $7 \mathrm{~h}$. The optical density at $600 \mathrm{~nm}$ was measured using a microplate spectrophotometer (Benchmark Plus, Bio-Rad).

\subsection{Inhibition by RA and SC of the Growth of V. vulnificus and V. parahaemolyticus}

Glycerol stocks of $V$. vulnificus and $V$. parahaemolyticus were prepared as for $V$. metschnikovii. Cells $(10 \mu \mathrm{L})$ from the glycerol stock were added to $10 \mathrm{~mL}$ NB medium supplemented with RA and SC. Culture was performed at $37^{\circ} \mathrm{C}$ for $7 \mathrm{~h}$. The optical density at $600 \mathrm{~nm}$ was measured using a microplate spectrophotometer (Benchmark Plus, Bio-Rad).

\subsection{Statistical Analysis}

The statistical significance was analyzed by one-way ANOVA followed by a Tukey HSD (honestly significant difference) post hoc test using R program (Version 3.6.0). $p \leq 0.05$ was considered to be statistically significant.

\section{Conclusions}

The advent of multidrug resistance among pathogenic bacteria is imperiling the utility of antibiotics. The inhibition of FbpA and iron uptake shows promise as an antibacterial. In this study, we have revealed the molecular mechanism of anti-Vibrio activity of RA. The growths of $V$. metschnikovii, V. vulnificus, and $V$. parahaemolyticus were inhibited significantly by RA and further inhibited by the supplementation of SC. The combination of RA and SC has high potential to be applied as a food preservative and bacteriostatic agent in the future. Moreover, such new bacteriostatic agents will reduce the excessive and inappropriate use of antibiotics in livestock, aquaculture, and plant agriculture as well as human and veterinary medicine. Further studies should evaluate the utility of RA/SC in various areas. 
Supplementary Materials: The following are available online at https: / www.mdpi.com/article/ $10.3390 /$ ijms222313010/s1.

Author Contributions: P.L.: Conceptualization, Funding Acquisition, Methodology, Project administration, Supervision, Formal Analysis, Software, Writing-Original Draft, Writing-Review and Editing. M.S. (Miaomiao Sui): Investigation. M.Z.: Investigation. M.W.: Investigation. T.K.: Investigation. K.O.: Writing—Review and Editing. H.I.: Writing—Review and Editing. S.O.: Writing-Review and Editing. M.S. (Michio Suzuki): Writing—Review and Editing. T.A.: Investigation, Writing-Review and Editing. T.F.: Investigation. K.N.: Conceptualization, Funding Acquisition, Methodology, Project Administration, Supervision, Writing-Original Draft, Writing-Review and Editing. All authors have read and agreed to the published version of the manuscript.

Funding: This work was supported in part by JSPS KAKENHI Grant Numbers JP18H02151 (to K.N.), JP19H05771 (to M.S. (Michio Suzuki)), and JP20K22561 (to P.L.) from Japan Society for the Promotion of Science.

Institutional Review Board Statement: Not applicable.

Informed Consent Statement: Not applicable.

Data Availability Statement: The crystal structure of apo VmFbpA (PDB: 7W3W) has been deposited in the Protein Data Bank (www.rcsb.org).

Acknowledgments: The X-ray diffraction experiments were performed at synchrotron beamlines BL44XU at SPring-8 (Hyogo, Japan) under the Cooperative Research Program of Institute for Protein Research, Osaka University (Proposal No. 2017B6733, 2018B6831, 2020A6528, and 2020B6528) and ARNE3A at Photon Factory (Ibaraki, Japan) under the approval of the Photon Factory Program Advisory Committee (Proposal No. 2020G681). We would like to thank the beamline staff members at SPring-8 BL44XU and Photon Factory AR-NE3A for their help with X-ray data collection and processing.

Conflicts of Interest: The authors declare that they have no conflict of interest.

\section{References}

1. Baker-Austin, C.; Oliver, J.D.; Alam, M.; Ali, A.; Waldor, M.K.; Qadri, F.; Martinez-Urtaza, J. Vibrio spp. infections. Nat. Rev. Dis. Prim. 2018, 4, 8. [CrossRef]

2. Bonnin-Jusserand, M.; Copin, S.; Le Bris, C.; Brauge, T.; Gay, M.; Brisabois, A.; Grard, T.; Midelet-Bourdin, G. Vibrio species involved in seafood-borne outbreaks (Vibrio cholerae, $V$. parahaemolyticus and $V$. vulnificus): Review of microbiological versus recent molecular detection methods in seafood products. Crit. Rev. Food Sci. Nutr. 2019, 59, 597-610. [CrossRef]

3. Pachauri, R.K.; Allen, M.R.; Barros, V.R.; Broome, J.; Cramer, W.; Christ, R.; Church, J.A.; Clarke, L.; Dahe, Q.; Dasgupta, P.; et al. Climate Change 2014: Synthesis Report. Contribution of Working Groups I, II and III to the Fifth Assessment Report of the Intergovernmental Panel on Climate Change; Pachauri, R.K., Meyer, L., Eds.; IPCC: Geneva, Switzerland, 2014.

4. Maggiore, A.; Afonso, A.; Barrucci, F.; Sanctis, G. De Climate change as a driver of emerging risks for food and feed safety, plant, animal health and nutritional quality. EFSA Support. Publ. 2020, 17, 1881E. [CrossRef]

5. Froelich, B.A.; Daines, D.A. In hot water: Effects of climate change on Vibrio-human interactions. Environ. Microbiol. 2020, 22, 4101-4111. [CrossRef] [PubMed]

6. Newton, A.; Kendall, M.; Vugia, D.J.; Henao, O.L.; Mahon, B.E. Increasing rates of vibriosis in the United States, 1996-2010: Review of surveillance data from 2 systems. Clin. Infect. Dis. 2012, 54 (Suppl. 5), S391-S395. [CrossRef]

7. Vibrio Species Causing Vibriosis. Available online: https://www.cdc.gov/vibrio/faq.html (accessed on 1 November 2021).

8. Matté, M.H.; Baldassi, L.; Barbosa, M.L.; Malucelli, M.I.C.; Nitrini, S.M.O.O.; Matté, G.R. Virulence factors of Vibrio metschnikovii strains isolated from fish in Brazil. Food Control 2007, 18, 747-751. [CrossRef]

9. Miller, R.A.; Harbottle, H. Antimicrobial drug resistance in fish pathogens. Microbiol. Spectr. 2018, 6, 213-238. [CrossRef]

10. Hameed, A.; Naveed, S.; Qamar, F.; Alam, T.; Abbas, S.S.; Sharif, N. Irrational use of antibiotics, in different age groups of karachi: A wakeup call for antibiotic resistance and future infections. J. Bioequiv. Availab. 2016, 8, 242-245. [CrossRef]

11. Payne, S.M.; Mey, A.R.; Wyckoff, E.E. Vibrio iron transport: Evolutionary adaptation to life in multiple environments. Microbiol. Mol. Biol. Rev. 2016, 80, 69-90. [CrossRef]

12. Wazen, R.M.; Kuroda, S.; Nishio, C.; Sellin, K.; Brunski, J.B.; Nanci, A. Iron in infection and immunity. Cell Host Microbe. 2014, 8, 1385-1395. [CrossRef]

13. Schaible, U.E.; Kaufmann, S.H.E. Iron and microbial infection. Nat. Rev. Microbiol. 2004, 2, 946-953. [CrossRef]

14. Parker Siburt, C.J.; Mietzner, T.A.; Crumbliss, A.L. FbpA-A bacterial transferrin with more to offer. Biochim. Biophys. Acta-Gen. Subj. 2012, 1820, 379-392. [CrossRef]

15. Maleki, A.; Ghafourian, S.; Pakzad, I.; Badakhsh, B.; Sadeghifard, N. mazE antitoxin of toxin antitoxin system and fbpA as reliable targets to eradication of Neisseria meningitidis. Curr. Pharm. Des. 2018, 24, 1204-1210. [CrossRef] [PubMed] 
16. Klančnik, A.; Piskernik, S.; Jeršek, B.; Možina, S.S. Evaluation of diffusion and dilution methods to determine the antibacterial activity of plant extracts. J. Microbiol. Methods 2010, 81, 121-126. [CrossRef]

17. Okamura, H.; Nishikiori, M.; Xiang, H.; Ishikawa, M.; Katoh, E. Interconversion of two GDP-bound conformations and their selection in an Arf-family small G protein. Structure 2011, 19, 988-998. [CrossRef]

18. Xiang, H.; Takeuchi, H.; Tsunoda, Y.; Nakajima, M.; Murata, K.; Ueguchi-Tanaka, M.; Kidokoro, S.I.; Kezuka, Y.; Nonaka, T.; Matsuoka, M.; et al. Thermodynamic characterization of OsGID1-gibberellin binding using calorimetry and docking simulations. J. Mol. Recognit. 2011, 24, 275-282. [CrossRef]

19. Lu, P.; Moriwaki, Y.; Zhang, M.; Katayama, Y.; Lu, Y.; Okamoto, K.; Terada, T.; Shimizu, K.; Wang, M.; Kamiya, T.; et al. Functional characterisation of two ferric-ion coordination modes of TtFbpA, the periplasmic subunit of an ABC-Type iron transporter from: Thermus thermophilus HB8. Metallomics 2019, 11, 2078-2088. [CrossRef] [PubMed]

20. Adomako-Bonsu, A.G.; Chan, S.L.; Pratten, M.; Fry, J.R. Antioxidant activity of rosmarinic acid and its principal metabolites in chemical and cellular systems: Importance of physico-chemical characteristics. Toxicol. Vitr. 2017, 40, 248-255. [CrossRef]

21. Erkan, N.; Ayranci, G.; Ayranci, E. Antioxidant activities of rosemary (Rosmarinus Officinalis L.) extract, blackseed (Nigella sativa L.) essential oil, carnosic acid, rosmarinic acid and sesamol. Food Chem. 2008, 110, 76-82. [CrossRef] [PubMed]

22. Lamien-Meda, A.; Nell, M.; Lohwasser, U.; Börner, A.; Franz, C.; Novak, J. Investigation of antioxidant and rosmarinic acid variation in the sage collection of the genebank in gatersleben. J. Agric. Food Chem. 2010, 58, 3813-3819. [CrossRef]

23. Bullen, J.J.; Leigh, L.C.; Rogers, H.J. The effect of iron compounds on the virulence of Escherichia coli for guinea-pigs. Immunology 1968, 15, 581-588. [PubMed]

24. Grosse, C.; Scherer, J.; Koch, D.; Otto, M.; Taudte, N.; Grass, G. A new ferrous iron-uptake transporter, EfeU (YcdN), from Escherichia coli. Mol. Microbiol. 2006, 62, 120-131. [CrossRef] [PubMed]

25. Braun, V.; Hantke, K. The Tricky Ways Bacteria Cope with Iron Limitation; Springer: Dordrecht, The Netherlands, 2013 ; pp. 31-66.

26. Braun, V. Iron uptake by Escherichia coli. Front. Biosci. 2003, 8, 1232. [CrossRef] [PubMed]

27. Cartron, M.L.; Maddocks, S.; Gillingham, P.; Craven, C.J.; Andrews, S.C. Feo-Transport of ferrous iron into bacteria. BioMetals 2006, 19, 143-157. [CrossRef] [PubMed]

28. Patzer, S.I.; Hantke, K. Dual repression by $\mathrm{Fe}^{2+}$-Fur and $\mathrm{Mn}^{2+}-\mathrm{MntR}$ of the mntH gene, encoding an NRAMP-like Mn ${ }^{2+}$ transporter in Escherichia coli. J. Bacteriol. 2001, 183, 4806-4813. [CrossRef]

29. Banerjee, S.; Paul, S.; Nguyen, L.T.; Chu, B.C.H.; Vogel, H.J. FecB, a periplasmic ferric-citrate transporter from E. coli, can bind different forms of ferric-citrate as well as a wide variety of metal-free and metal-loaded tricarboxylic acids. Metallomics 2016, 8, 125-133. [CrossRef]

30. Balado, M.; Puentes, B.; Couceiro, L.; Fuentes-Monteverde, J.C.; Rodríguez, J.; Osorio, C.R.; Jiménez, C.; Lemos, M.L. Secreted citrate serves as iron carrier for the marine pathogen Photobacterium damselae subsp damselae. Front. Cell. Infect. Microbiol. 2017, 7, 361. [CrossRef]

31. McHugh, J.P.; Rodríguez-Quiñones, F.; Abdul-Tehrani, H.; Svistunenko, D.A.; Poole, R.K.; Cooper, C.E.; Andrews, S.C. Global iron-dependent gene regulation in Escherichia coli: A new mechanism for iron homeostasis. J. Biol. Chem. 2003, 278, 29478-29486. [CrossRef]

32. Carrano, C.J.; Raymond, K.N. Ferric Ion Sequestering Agents. 2. Kinetics and mechanism of iron removal from transferrin by enterobactin and synthetic tricatechols. J. Am. Chem. Soc. 1979, 101, 5401-5404. [CrossRef]

33. Walsh, C.T.; Liu, J.; Rusnak, F.; Sakaitani, M. Molecular studies on enzymes in chorismate metabolism and the enterobactin biosynthetic pathway. Chem. Rev. 1990, 90, 1105-1129. [CrossRef]

34. Tetsumoto, S. Bactericidal activity of various seasonings against Salmonella enterica subsp. enterica serovar Typhi and Vibrio cholerae. J. Agric. Chem. Soc. Jpn. 1934, 10, 123-127. [CrossRef]

35. Corral-Lugo, A.; Daddaoua, A.; Ortega, A.; Espinosa-Urgel, M.; Krell, T. Rosmarinic acid is a homoserine lactone mimic produced by plants that activates a bacterial quorum-sensing regulator. Sci. Signal. 2016, 9, ra1. [CrossRef] [PubMed]

36. Trott, O.; Olson, A.J. Software news and update AutoDock Vina: Improving the speed and accuracy of docking with a new scoring function, efficient optimization, and multithreading. J. Comput. Chem. 2010, 31, 455-461. [CrossRef] [PubMed] 